\title{
The anti-HER3 (ErbB3) therapeutic antibody 9F7-F11 induces HER3 ubiquitination and degradation in tumors through JNK1/2- dependent ITCH/AIP4 activation
}

\author{
Christophe Le Clorennec ${ }^{1,2,3,4}$, Yassamine Lazrek ${ }^{1,2,3,4,5,8}$, Olivier Dubreuil ${ }^{5,9}$, Christel \\ Larbouret $^{1,2,3,4}$, Marie-Alix Poul ${ }^{1,2,3,4}$, Philippe Mondon ${ }^{5,10}$, Gerry Melino ${ }^{6,7}$, André \\ Pèlegrin ${ }^{1,2,3,4}$, Thierry Chardès ${ }^{1,2,3,4}$ \\ ${ }^{1}$ IRCM, Institut de Recherche en Cancérologie de Montpellier, Montpellier, F-34298, France \\ ${ }^{2}$ INSERM, U1194 Montpellier, Montpellier, F-34298, France \\ 3 Université de Montpellier, Montpellier, F-34298, France \\ ${ }^{4}$ ICM, Institut Régional du Cancer Montpellier, Montpellier, F-34298, France \\ ${ }^{5}$ Millegen SA, Labège, F-31670, France \\ ${ }^{6}$ Biochemistry Laboratory, Instituto Dermopatico Dell'Immacolata, Department of Experimental Medicine and Surgery, \\ University of Rome "Tor Vergata," 00133 Rome, Italy \\ ${ }^{7}$ Toxicology Unit, Medical Research Council, Leicester University, Leicester LE1 9HN, United Kingdom \\ ${ }^{8}$ Institut Pasteur de Guyane, BP 6010, 97306, Cayenne Cedex, France \\ ${ }^{9}$ GamaMabs Pharma SA, Centre Pierre Potier, ONCOPOLE, BP 50624, France \\ ${ }^{10}$ LFB Biotechnologies, 59000, Lille, France
}

Correspondence to: Thierry Chardès, email: thierry.chardes@inserm.fr

Keywords: cancer, HER3, ITCH/AIP4, antibody, treatment

Received: January 06, 2016 Accepted: April 16, $2016 \quad$ Published: May 18, 2016

\section{ABSTRACT}

We characterized the mechanism of action of the neuregulin-non-competitive anti-HER3 therapeutic antibody 9F7-F11 that blocks the PI3K/AKT pathway, leading to cell cycle arrest and apoptosis in vitro and regression of pancreatic and breast cancer in vivo. We found that 9F7-F11 induces rapid HER3 down-regulation. Specifically, 9F7-F11-induced HER3 ubiquitination and degradation in pancreatic, breast and prostate cancer cell lines was driven mainly by the itchy E3 ubiquitin ligase (ITCH/AIP4). Overexpression of the ITCH/AIP4 inhibitor N4BP1 or small-interfering RNA-mediated knockdown of ITCH/AIP4 inhibited HER3 ubiquitination/degradation and PI3K/AKT signaling blockade induced by 9F7-F11. Moreover, 9F7-F11-mediated JNK1/2 phosphorylation led to ITCH/AIP4 activation and recruitment to HER3 for receptor ubiquitination and degradation. ITCH/AIP4 activity was activated by the deubiquitinases USP8 and USP9X, as demonstrated by RNA interference. Taken together, our results suggest that 9F7-F11-induced HER3 ubiquitination and degradation in cancer cells mainly occurs through JNK1/2-dependent ITCH/AIP4 activation.

\section{INTRODUCTION}

HER3/ErbB3 is a member of the human epidermal growth factor receptor (EGFR) family [1] and HER3 expression has been correlated with tumor progression and reduction of patient survival in pancreatic, breast, ovarian and gastric cancer, in head and neck squamous cell carcinoma and in melanoma [2-7]. Therefore, much effort is currently focused on the development of anti-HER3 therapeutic antibodies for cancer treatment $[8,9]$. Most of these molecules block the NRG-1 binding site [10-12]; however, HER3 can act through ligand-independent and -dependent oncogenic mechanisms [13] via paracrine or autocrine loops [14]. This allowed us to generate the neuregulin-non-competitive anti-HER3 antibody 9F7-F11 that blocks the PI3K/AKT pathway, leading to in vivo 
tumor regression [15]. Interestingly, a strong HER3 downregulation is observed in vitro in tumor cells co-incubated with 9F7-F11 and NRG-1 [15]. Here, we investigated the molecular mechanisms of HER3 degradation induced by 9F7-F11 to better understand the anti-cancer efficiency of this therapeutic antibody.

Proteasomal or lysosomal degradation of tyrosine kinase receptors, and particularly of EGFR family receptors, is regulated by ubiquitination [16, 17]. E3 ubiquitin ligases have crucial roles in regulating EGFR family receptor levels [18]. The RING-finger E3 ubiquitin ligase CBL binds to EGFR and favors its ubiquitination for lysosomal degradation [19], whereas the E3 ubiquitin ligase CHIP promotes HER2 ubiquitination/degradation [20]. Other HECT family E3 ligases, such as WW domain containing protein 1 (WWP1) and itchy E3 ubiquitin protein ligase (ITCH/AIP4), ubiquitinate HER4, leading to its proteasomal and lysosomal degradation [21,22]. Dysregulation of EGFR ubiquitination/degradation has been related to resistance to cetuximab [23]. The therapeutic efficiency of anti-EGFR, -HER2 and -c-MET antibodies, used alone or in combination, is associated with an increase of receptor ubiquitination and degradation in tumor cells [24-30], sometimes mediated by the E3 ubiquitin ligase CBL [28,29]. The RING-finger E3 ubiquitin ligase neuregulin receptor degradation protein-1 (Nrdp1) and the HECT family E3 neural precursor cell expressed, developmentally downregulated 4 (NEDD4) ubiquitinate HER3 in basal condition and after NRG-1 stimulation [31-33], but nothing is known about the mechanisms of drug-induced HER3 degradation/ubiquitination.

Here, we show that the E3 ubiquitin ligase ITCH/ AIP4 binds to HER3 and activates HER3 ubiquitination and degradation induced by 9F7-F11. ITCH knock-down by small interfering RNA abrogated 9F7-F11-induced HER3 ubiquitination and proteasomal degradation in pancreatic, prostate and breast cancer cells. 9F7-F11mediated ITCH activation occurred in a JNK1/2dependent manner and was activated by the ITCH-specific deubiquitinases USP8 and USP9X. Collectively, these data demonstrate that the anti-HER3 therapeutic antibody 9F7-F11 promotes HER3 degradation to inhibit the progression of HER3-dependent tumors.

\section{RESULTS}

\section{The anti-HER3 antibody 9F7-F11 induces HER3 degradation both in NRG-1 $\beta$-stimulated and non-stimulated pancreatic, prostate and breast cancer cells}

To temporally characterize 9F7-F11-induced HER3 degradation, we incubated pancreatic $\mathrm{BxPC} 3$ and prostate DU145 cancer cells with 9F7-F11 in the presence or not of NRG-1 $\beta$. In BxPC3 cells, 1 to 2 hr-incubation with 9F7-F11 reduced HER3 expression by 20 and $40 \%$, respectively, compared to control cells (medium alone) (Figure 1A). The antibody effect was earlier (after $10 \mathrm{~min}$ incubation) and stronger (up to $90 \%$ reduction of HER3 expression after $2 \mathrm{hr}$ ) in DU145 prostate cells (Figure 1B). After $48 \mathrm{hr}$, HER3 re-expression was not observed (Figure 1A) in BxPC3 cells, suggesting that 9F7-F11 has a sustained effect on HER3 degradation and does not induce transcription to maintain HER3 expression, as observed following stimulation with NRG-1 $\beta$ [34]. In contrast, treatment of $\mathrm{BxPC} 3$ cells with irrelevant control antibody Px did modify neither HER3 expression and phosphorylation, nor subsequent downstream cell signaling (Supplementary Figure S1). In cells co-incubated with NRG-1 $\beta$, 9F7-F11 effect on HER3 degradation was stronger. HER3 expression was almost completely abrogated in BxPC3 cells after $2 \mathrm{hr}$ of co-incubation (Figure 1A) and in DU145 cells after only $30 \mathrm{~min}$ (Figure 1B); such antibody-induced HER3 degradation being confirmed in MDA-MB468 triple-negative breast cancer (Supplementary Figure S2). NRG1- $\beta$ stimulation alone did not induce HER3 down-regulation in BxPC3 cells during the $2 \mathrm{hr}$ of the experiment (Figure 1A). Conversely, HER 3 expression was progressively reduced in DU145 cells after 2 hr-stimulation with NRG1- $\beta$, albeit to a lower extent than with 9F7-F11 (Figure 1B), probably due to faster HER3 turnover. Incubation with 9F7-F11 also inhibited phosphorylation of HER3, AKT and ERK1/2 (Figure 1A and 1B). This effect was stronger in cells co-incubated with NRG-1 $\beta$. A lower efficiency of antibody 9F7-F11 on pERK1/2 was observed in DU145 cells, probably due to the fact that this prostate cancer cell line exhibits KRAS mutation G12V [35]. Conversely, NRG- $1 \beta$ stimulation alone promoted HER3, AKT and ERK1/2 phosphorylation.

\section{F7-F11-induced HER3 degradation occurs mainly through the proteasome pathway}

To determine the pathways involved in 9F7-F11induced HER3 degradation, we co-incubated BxPC3 cells for $4 \mathrm{hr}$ with 9F7-F11, NRG-1 $\beta$ or medium alone after pre-incubation with the proteasome inhibitor MG132, the lysosome inhibitor chloroquine or both. Without antibody treatment (medium alone), and consistent with previous studies [32], $4 \mathrm{hr}$-incubation with chloroquine ( $\mathrm{SI}=1.8$ ) and, to a lower extent, with MG132 (SI = 1.2), led to HER3 accumulation (Figure 2). 9F7-F11-induced HER3 decrease $(\mathrm{SI}=0.2)$ was substantially reduced by preincubation with MG132 (SI = 0.6) and, to a lower extent, with chloroquine (0.4). Combination of the two inhibitors restored HER3 expression (Figure 2). This suggests that 9F7-F11-induced degradation mainly occurs through the proteasome pathway, with a minor contribution from the lysosome pathway. NRG-1 $\beta$-induced HER3 degradation was mainly via the proteasome pathway (Figure 2), as previously shown upon $3 \mathrm{hr}$-ligand activation [32]. 

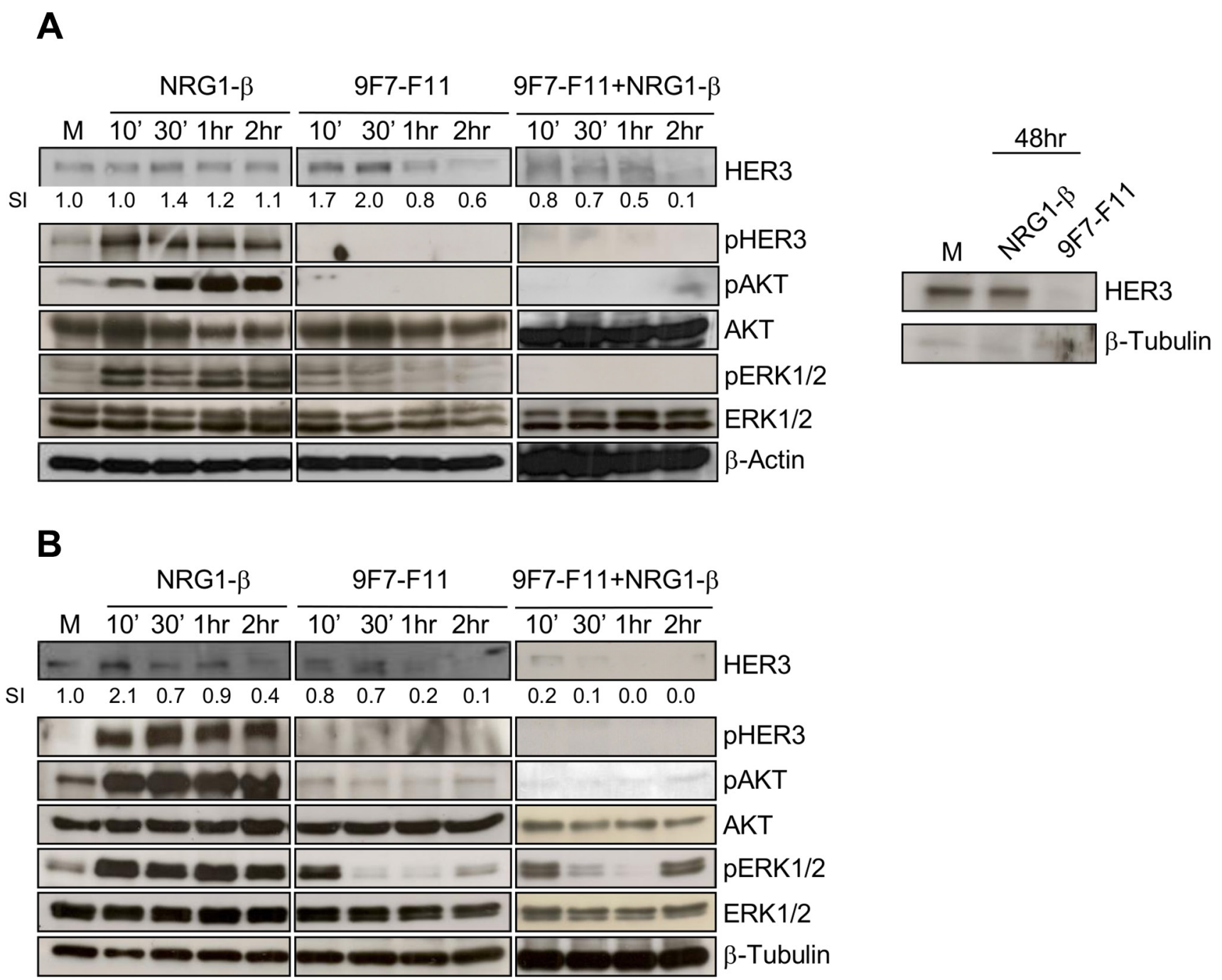

Figure 1: The anti-HER3 antibody 9F7-F11 inhibits NRG1- $\beta$-induced HER3 activation, leading to the blockade of the AKT and ERK pathways, and to HER3 degradation in cancer cells. Pancreatic BxPC3 (A) and prostatic DU145 (B) cancer cells were starved in $1 \%$ serum for $24 \mathrm{hr}$ before incubation with $100 \mathrm{ng} / \mathrm{mL} \mathrm{NRG-1 \beta}$ or/and with $50 \mu \mathrm{g} / \mathrm{mL}$ of the anti-HER3 antibody 9F7-F11 for the indicated times. Quantification of the HER3 signal intensity (SI) with ImageJ is indicated below the images (relative to control). $\beta$-actin was evaluated as loading control.

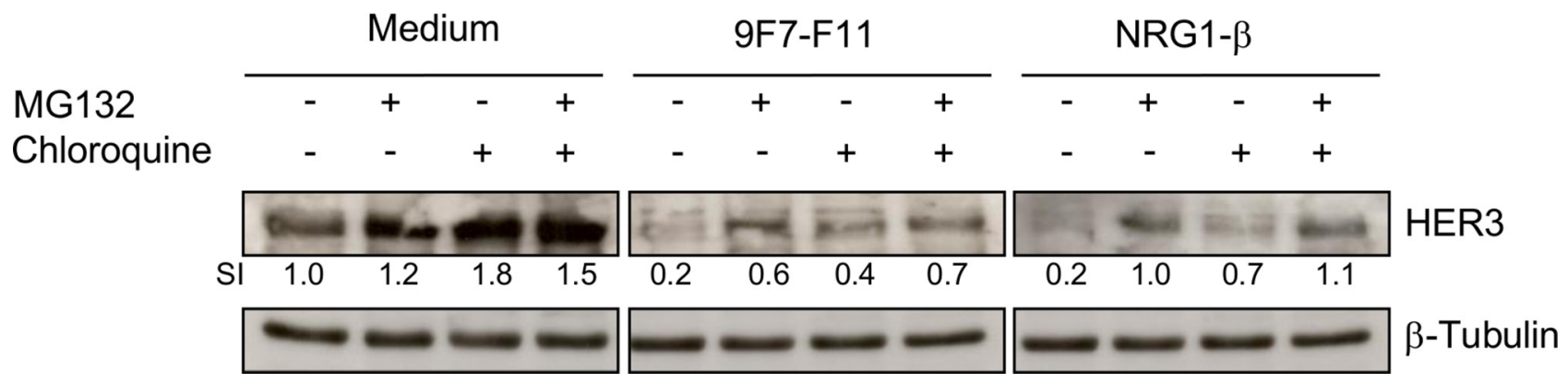

Figure 2: 9F7-F11-induced HER3 degradation mainly occurs through the proteasome pathway. Serum-starved BxPC3 cells were pre-incubated with $10 \mu \mathrm{M}$ of the proteasome inhibitor MG132 and/or with $100 \mu \mathrm{M}$ of the lysosome inhibitor chloroquine for $4 \mathrm{hr}$, before addition of $50 \mu \mathrm{g} / \mathrm{mL}$ 9F7-F11 or $100 \mathrm{ng} / \mathrm{mL}$ NRG-1 $\beta$ for $4 \mathrm{hr}$. After cell lysis, HER3 protein expression was assessed in whole cell lysates by western blotting using the anti-HER3 antibody C-17. $\beta$-tubulin was evaluated as loading control. HER3 protein level was measured with the ImageJ software and indicated as Signal Intensity (SI) relative to control. 


\section{The RING E3 ubiquitin ligase Nrdp1 is involved in NRG-1 $\beta$-mediated, but not in 9F7-F11- induced HER3 degradation in BxPC3 cells}

HER3 can be ubiquitinated by Nrdp1 for proteasomal degradation, both in basal conditions and after NRG- $1 \beta$ stimulation $[32,36]$. To determine whether Nrdp1 is involved in 9F7-F11-induced HER3 degradation, we knocked-down the Nrdpl gene by transfecting BxPC3 cells with a specific siRNA (siNrdp1) before incubation with 9F7-F11 or NRG-1 $\beta$ for $4 \mathrm{hr}$. Nrdp1 protein level was reduced by $80 \%$ in $\mathrm{Nrdp} 1$-silenced BxPC3 cells compared to BxPC3 cells transfected with scramble siRNA (siSC) in all experimental conditions (Figure 3A). When cells were incubated with medium alone, $N r d p 1$ silencing increased HER3 protein level by 2-fold (Figure 3A), and also AKT and ERK1/2 phosphorylation (Figure 3B), compared to siSC-transfected cells. Treatment of BxPC3 cells with control antibody Px did not modify Nrdp1 expression (Supplementary Figure S1). As expected [36], Nrdp1 silencing blocked NRG-1 $\beta$-induced HER3 degradation induced after long term-ligand incubation ( $4 \mathrm{hr}$ ), compared to siSC (Figure 3A and 3B), confirming that Nrdp1 is involved in NRG-1 $\beta$-mediated HER3 degradation. Conversely, Nrdp1 silencing did not affect 9F7-F11induced HER3 degradation (Figure 3A).

\section{The anti-HER3 antibody 9F7-F11 induces recruitment of the $\mathrm{E} 3$ ubiquitin ligase ITCH for HER3 ubiquitination}

The E3 ubiquitin ligases ITCH/AIP4, NEDD4 and WWP1 from the HECT family decrease HER4 protein level $[21,22,37,38]$. ITCH/AIP4 binds directly to the ${ }^{1153} \mathrm{PPX}(\mathrm{A}) \mathrm{Y}^{1156}$ motif in the CYT1 domain of HER4 [37]. HER3 and HER4 protein sequence alignment revealed a $\operatorname{PPX}(\mathrm{R}) \mathrm{Y}$ binding motif (amino acids 972 to 975 ) in HER3 C-terminal tail (Figure 4A) that could potentially be involved in HER3/ITCH interaction.

To assess whether HER3 binds to ITCH, we immunoprecipitated with a C-terminal tail-specific anti-HER3 antibody (HER3 Ab) protein extracts from BxPC3 cells (Figure 4B and Supplementary Figure S3) following pre-incubation with medium alone (control), 9F7-F11 or NRG-1 $\beta$. In the absence of HER3 Ab for immunoprecipitation (Figure 4B) no HER3 detection was observed in the immunoprecipitation extract whereas HER3 was evidenced in the whole cell lysate. When HER3 Ab was added, ITCH was co-immunoprecipitated with HER3 only in cells incubated with 9F7-F11 or NRG-1 $\beta$. The absence of ITCH recruitment in control cells treated with medium alone suggests that ITCH needs to be activated to bind to its substrates, as previously demonstrated in HEK293 cells [39]. Normal control antibody did immunoprecipitate neither HER3 nor ITCH (Supplementary Figure S3). The same HER3 motif was recently identified as the NEDD4 binding site for HER3 ubiquitination and degradation, independently of NRG-1 $\beta$ stimulation [33]. Therefore, we used an anti-NEDD4 antibody to check whether NEDD4 was co-immunoprecipitated with HER3 in BxPC3 cells (Figure 4B). Differently from ITCH, NEDD4 co-immunoprecipitated with HER3 only in basal conditions (medium alone), but not after incubation with 9F7-F11 or with NRG-1 $\beta$, as previously shown [33]. 9F7-F11-induced abrogation of NEDD4/HER3 interaction could be due to competition between ITCH and NEDD4 for the same binding site on HER3, with ITCH replacing NEDD4 upon 9F7-F11 treatment. Taken together, these results show that 9F7-F11 induces the direct recruitment of ITCH on HER3 to drive HER3 degradation in BxPC3 cells.

As ITCH ubiquitinates receptors of the EGFR family [37], we asked whether 9F7-F11-induced ITCH recruitment could lead to HER3 ubiquitination. We immunoprecipitated with an anti-HER3 antibody extracts of BxPC3 cells pre-incubated with MG132 and then incubated with medium alone (control), 9F7-F11 or/and NRG-1 $\beta$ (Figure 4C). Analysis of HER3 ubiquitination in the immunoprecipitates showed that HER3 ubiquitination increased upon incubation with 9F7-F11, with or without NRG-1 $\beta$, compared to control. HER3 ubiquitination was also observed, but at a lower level, in mediumtreated cells; this effect being probably due to NEDD4mediated ubiquitination at steady state [33]. Reduction of HER3 ubiquitination following 2-3 hr-treatment with antibody plus NRG-1 $\beta$ could be due to ligand-mediated ITCH auto-ubiquitination and further degradation [40]. Antibody-induced HER3 ubiquitination was confirmed in MDA-MB468 breast cancer cells (Supplementary Figure S4). In MDA-MB468 cells transiently transfected with plasmids expressing wild type $\mathrm{Myc-ITCH}$ and HA-ubiquitin, incubation with 9F7-F11 induced HER3 ubiquitination (Figure 4D). Taken together, these results show that the anti-HER3 antibody 9F7-F11 induces ITCH recruitment for HER3 ubiquitination and degradation.

\section{Overexpression of the ITCH inhibitor N4BP1 inhibits 9F7-F11-induced HER3 ubiquitination and degradation and stabilizes HER3 expression}

We transiently overexpressed NEDD4 Binding Protein-1 (N4BP1; a specific ITCH inhibitor) [41] with HA-ubiquitin and wild type Myc-ITCH in BxPC3 (Figure 5) and MDA-MB468 (Supplementary Figure S5) cells, and tested HER3 ubiquitination by immunoprecipitation and western blotting. 9F7-F11induced HER3 ubiquitination was abrogated by N4BP1 overexpression in $\mathrm{BxPC} 3$ cells (Figure 5A). Moreover, N4BP1 overexpression inhibited 9F7-F11-induced HER3/ ITCH interaction (Figure 5A); such effect being also demonstrated with another anti-HER3 antibody in MDAMB468 cells (Supplementary Figure S5). Transfection of wild type Myc-ITCH did not enhance 9F7-F11-induced 
HER3 ubiquitination, probably due to the fact that ITCH activity is tightly regulated by auto-ubiquitination leading to its degradation [40, 42, 43]. To better understand N4BP1 role in HER3 protein stability, we transfected increasing concentrations of the V5-N4BP1 plasmid in BxPC3 cells. N4BP1 overexpression enhanced HER3 expression in a dose-dependent manner, compared to control (mock) (Figure 5B) in NRG1-stimulated cells, suggesting that NRG1-induced degradation could be controlled by ITCH, as proposed by others [36, 44]. Similar results were obtained following incubation of N4BP1-overexpressing cells with 9F7-F11. Conversely, HER3 levels were reduced upon 9F7-F11 addition in control cells. These results demonstrate that ITCH inhibition by N4BP1 reduces 9F7-F11-induced HER3 degradation and strengthen the hypothesis that ITCH is the main driver of 9F7-F11-induced HER3 ubiquitination and degradation.
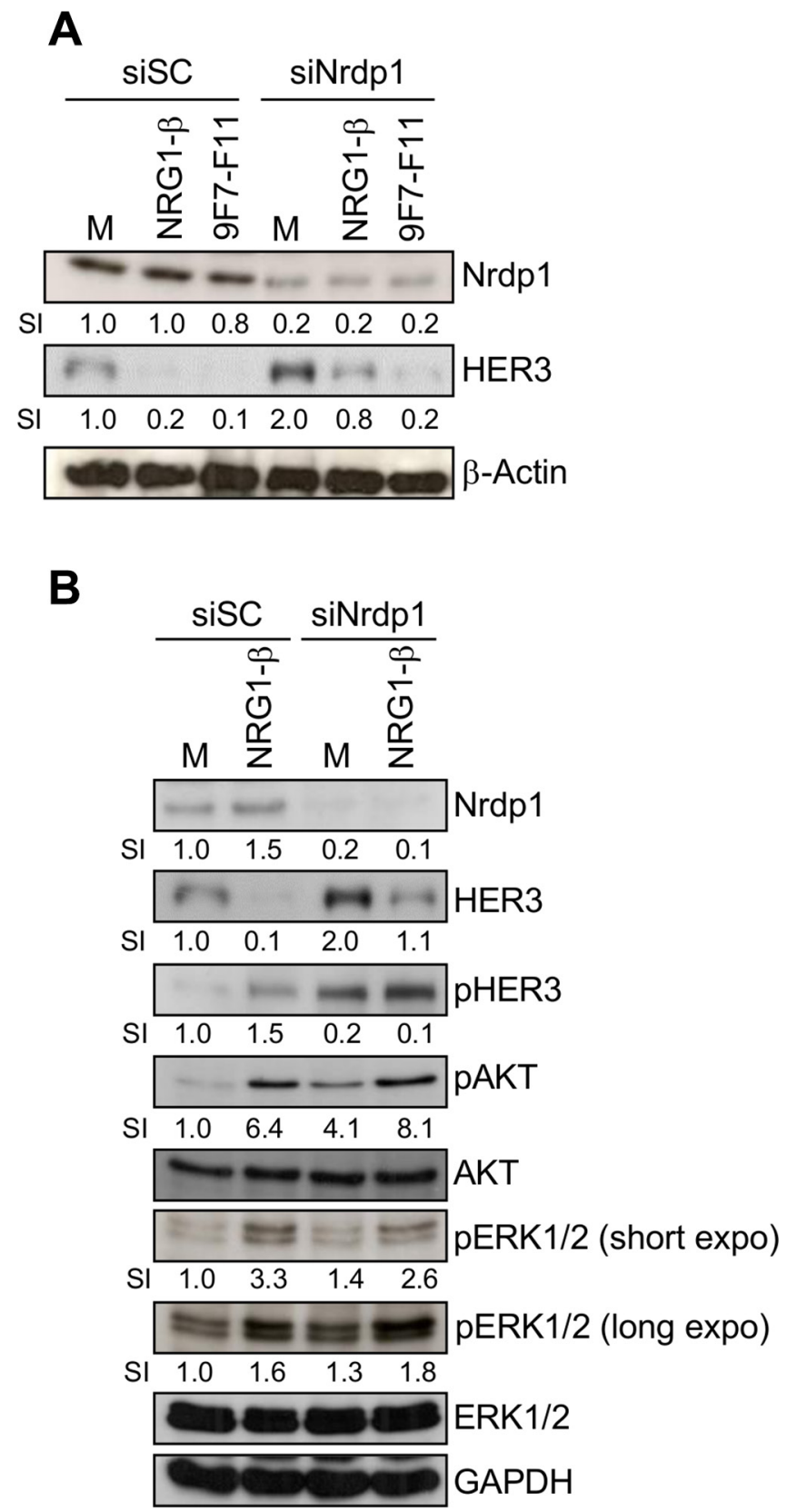

Figure 3: The E3 ubiquitin ligase Nrdp1 is involved in NRG1- $\beta$-induced, but not in 9F7-F11-induced HER3 degradation in pancreatic BxPC3 cells. (A) Cells were transfected with $50 \mathrm{nM}$ of the anti-Nrdp1 siRNA (siNrdp1) or Scramble Control (siSC) for $72 \mathrm{hr}$. After starvation, cells were then incubated with $50 \mu \mathrm{g} / \mathrm{mL}$ 9F7-F11 or $100 \mathrm{ng} / \mathrm{mL} \mathrm{NRG}-1 \beta$ for $4 \mathrm{hr}$. After cell lysis, HER3 and Nrdp1 expression were assessed in whole protein extracts by western blotting. The signal intensity (SI) (relative to control) was quantified with ImageJ and $\beta$-actin was used as loading control. (B) Cells transfected with siSC or siNrdp1 were stimulated with NRG-1 $\beta$ for 4 hr. HER3 and Nrdp1 expression as well as HER3, AKT and ERK1/2 phosphorylation were assessed in whole protein extracts by western blotting. GAPDH was used as loading control. 


\section{ITCH silencing inhibits 9F7-F11-induced HER3} degradation/downstream signaling blockade and 9F7-F11-induced HER3 ubiquitination

We knocked-down the $I T C H$ gene by transfecting BxPC3 (Figure 6A) and DU145 (Figure 6B) cells with a specific siRNA (siITCH) for $72 \mathrm{hr}$, before incubation with 9F7-F11 or NRG-1 $\beta$. ITCH expression was reduced in silTCH-transfected cells, compared to siSC-transfected cells, in all conditions. In basal conditions (medium alone), siSC did not affect HER3 expression. 9F7-F11induced reduction of HER 3 expression, observed in siSCtransfected cells, was inhibited in siTCH-transfected BxPC3 (Figure 6A) and DU145 (Figure 6B) cells.

A

\section{Homologous motif on HER3}

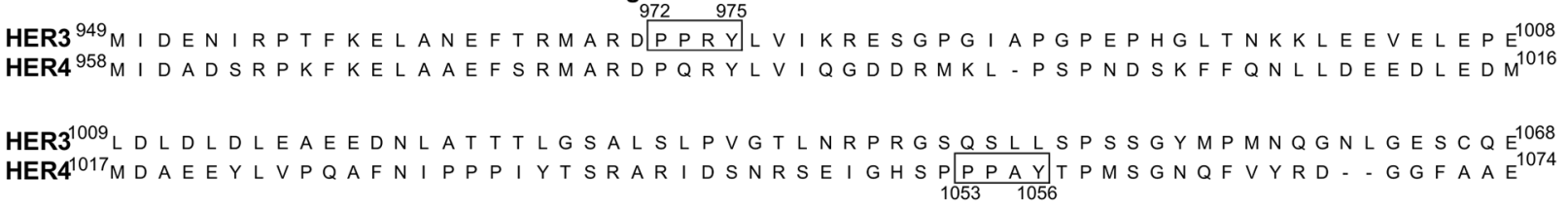

ITCH-binding motif on HER4 (Ref. 37)
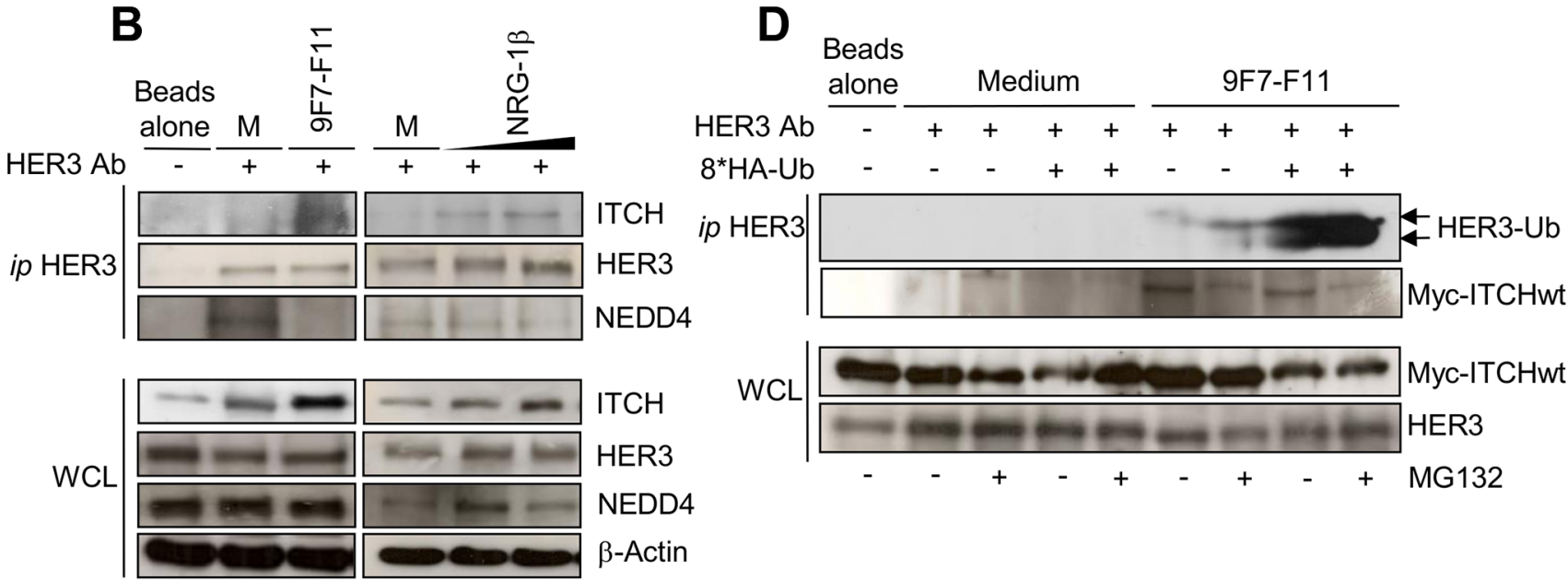

C
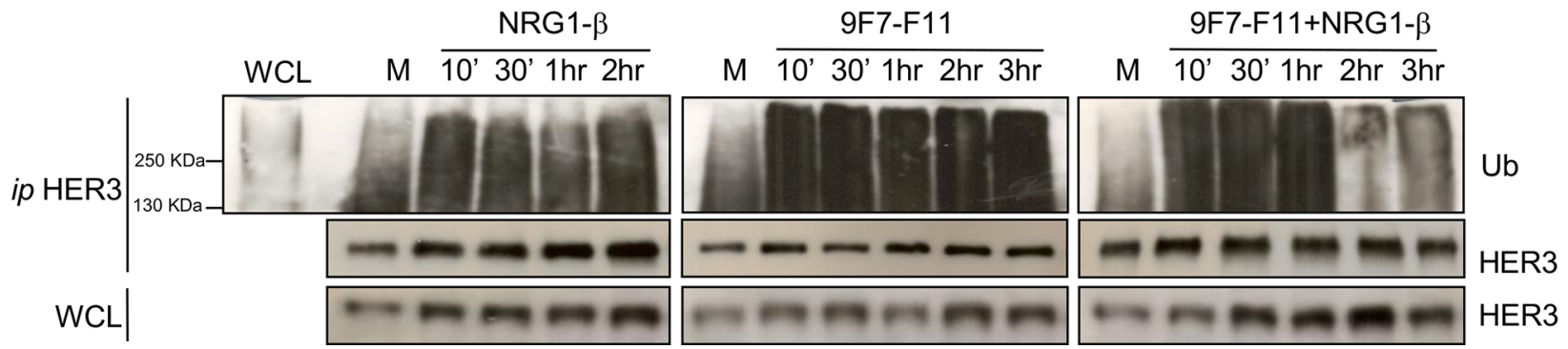

Figure 4: ITCH interacts with HER3 and the anti-HER3 antibody 9F7-F11 induces ITCH recruitment leading to HER3 ubiquitination and disruption of NEDD4/HER3 interaction. (A) Protein sequence alignment of HER3 and HER4 C-terminal tails showing the homology between the HER3 ${ }^{972}$ PPRY ${ }^{975}$ motif and the ITCH-binding motif ${ }^{1053}$ PPAY ${ }^{1056}$ in HER4. (B) Serum-starved BxPC3 cells were incubated with $50 \mu \mathrm{g} / \mathrm{mL}$ 9F7-F11 for $30 \mathrm{~min}$ or with $100 \mathrm{ng} / \mathrm{mL} \mathrm{NRG-1 \beta}$ for $30 \mathrm{~min}$ or $1 \mathrm{hr}$. After immunoprecipitation (ip) of $2 \mathrm{mg}$ of total protein extracts with an anti-HER3 monoclonal antibody against HER3 C-terminal tail (HER3 Ab), ITCH, HER3 and NEDD4 were detected by western blotting. (C) Serum-starved BxPC3 cells were pre-incubated with $10 \mu \mathrm{M}$ MG132 for 4 hr before incubation with $50 \mu \mathrm{g} / \mathrm{mL}$ 9F7-F11 with or without $100 \mathrm{ng} / \mathrm{mL} \mathrm{NRG-1 \beta}$ for the indicated times. After immunoprecipitation with HER3 Ab, HER3 ubiquitination status was assessed by western blotting using a specific anti-ubiquitin antibody (Ub). (D) MDA-MB468 cells were transfected with the Myc-ITCH plasmid and the HA-Ubiquitin plasmid or not for $24 \mathrm{hr}$. Then, cells were incubated with $20 \mu \mathrm{M}$ MG132 for $5 \mathrm{hr}$ before addition of $50 \mu \mathrm{g} / \mathrm{mL}$ 9F7-F11 for $2 \mathrm{hr}$. After immunoprecipitation with HER3 Ab, HER3 was probed with an ubiquitin-specific antibody as in (C). WCL, whole cell lysate. 
This confirms ITCH role in 9F7-F11-induced HER3 degradation. Interestingly, ITCH silencing increased HER3 expression either in basal conditions or in 9F7-F11-treated BxPC3 cells, suggesting a more complex crosstalk between E3 ubiquitin ligases [18, 33], deubiquitinases [36, 45, 46] and regulating proteins $[40,42,43]$. Similar results were obtained when cells were stimulated with NRG-1 $\beta$ (Figure 6A and 6B). ITCH silencing also decreased 9F7F11-triggered ITCH phosphorylation and inhibited 9F7F11 blockade on HER3, AKT and ERK phosphorylation (Figure 6A and 6B). Nrdp1 and NEDD4 expression were not affected in siSC- and siTCH-transfected cells in all conditions (Figure 6A and 6B). Irrelevant control antibody Px did modify neither HER3 pathway nor ITCH and NEDD4 expression (Supplementary Figure S1). To confirm that NEDD4 is not involved in 9F7-F11-induced HER3 degradation, we silenced the NEDD4 gene alone, or in combination with $I T C H$, in BxPC3 cells (Supplementary Figure S6). NEDD4 silencing did not abrogate 9F7F11-induced HER3 degradation and had no effect on the antibody-mediated blockade of HER3 downstream signaling. Conversely, concomitant NEDD4 and ITCH silencing inhibited 9F7-F11-induced HER3 degradation and restored HER3 phosphorylation, leading to AKT and ERK phosphorylation (Supplementary Figure S6). These results demonstrate ITCH direct role in 9F7-F11-induced

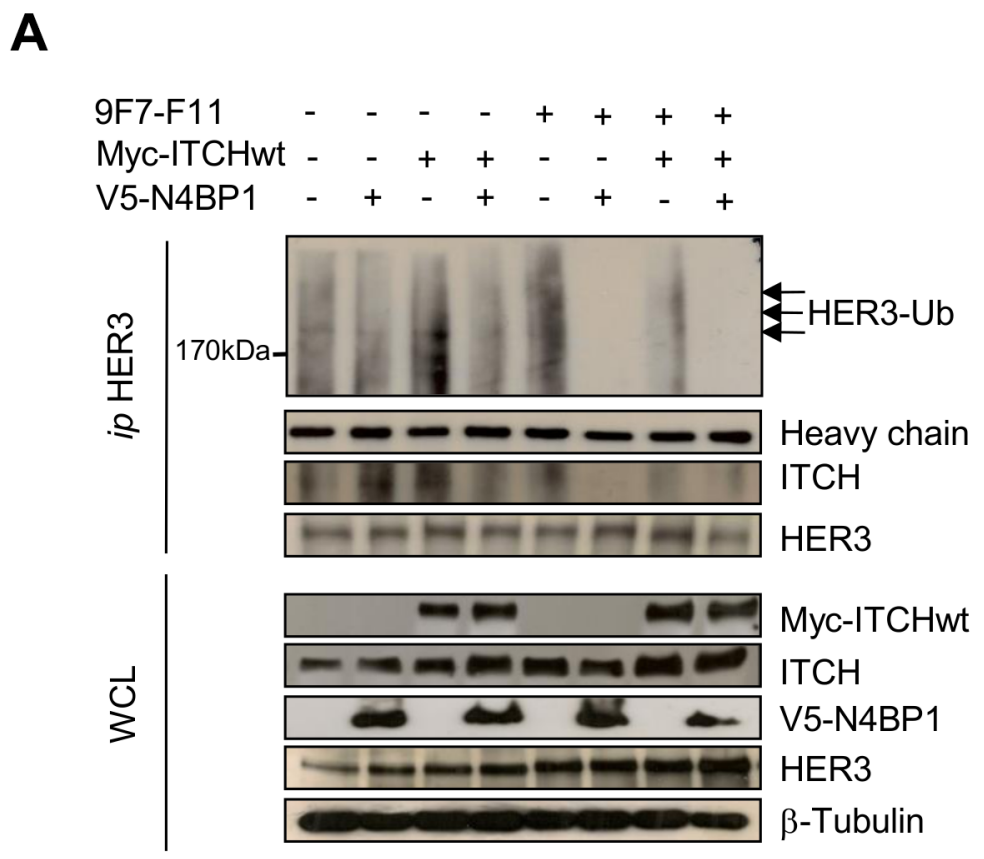

B

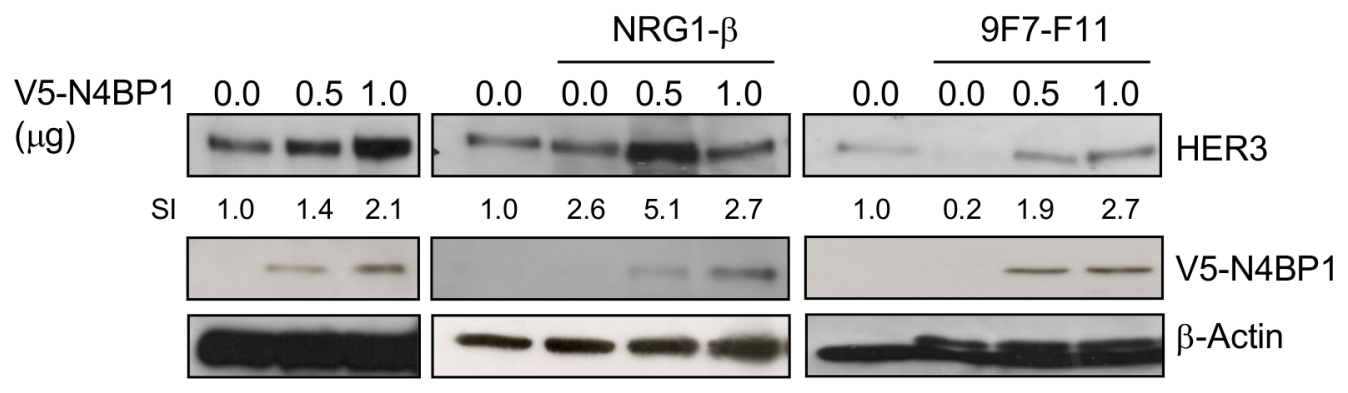

Figure 5: N4BP1 overexpression inhibits 9F7-F11-mediated HER3 ubiquitination and degradation induced by ITCH, and promotes HER3 protein stabilization in BxPc3 cells. (A) Cells were co-transfected with the Myc-ITCHwt, HA-Ub and/or GFP-N4BP1 plasmids for $24 \mathrm{hr}$. Transfected cells were then incubated with $20 \mu \mathrm{M}$ MG132 for $5 \mathrm{hr}$ before addition of $50 \mu \mathrm{g} / \mathrm{mL} 9 \mathrm{~F} 7-\mathrm{F} 11$ for $3 \mathrm{hr}$. After cells lysis with the CHAPS buffer and immunoprecipitation with the HER3 Ab, the ubiquitination status was analyzed by western blotting using an anti-HA antibody. HER3 and ITCH were detected using specific antibodies. (B) Cells were transfected with increasing doses of the V5-N4BP1 plasmid for $24 \mathrm{hr}$, and then incubated with $50 \mu \mathrm{g} / \mathrm{mL}$ 9F7-F11 or with $100 \mathrm{ng} / \mathrm{mL}$ NRG-1 $\beta$ for $3 \mathrm{hr}$. HER3 expression was assessed in whole cell lysates by western blotting. The V5-HRP antibody was used to detect N4BP1, and $\beta$-actin was the loading control. The signal intensity (SI) of the different bands was quantified with ImageJ. WCL, whole cell lysates. 
HER3 degradation. To confirm ITCH involvement in 9F7-F11-induced HER3 ubiquitination, we analyzed HER3 ubiquitination using an anti-poly-ubiquitin chain antibody after immunoprecipitation with an anti-HER3 antibody of extracts from $I T C H$-silenced BxPC3 cells incubated with 9F7-F11 or NRG-1 $\beta$ for $4 \mathrm{hr}$ (Figure 6C). Irrelevant control antibody Px did not immunoprecipitate the HER3 receptor (Figure 6C). The strong HER3 polyubiquitination induced by 9F7-F11 in siSC-transfected cells was abrogated in $I T C H$-silenced cells. This result confirms the direct involvement of ITCH in HER3 ubiquitination upon incubation with 9F7-F11.

\section{The anti-HER3 antibody 9F7-F11 activates ITCH through JNK1/2 phosphorylation}

Upon activation through JNK1/2-induced phosphorylation on Thr222, ITCH/AIP4 conformation changes from close to open, allowing substrate accessibility to its WW domains [39]. To determine whether JNK $1 / 2$ mediates ITCH activation during 9F7-F11-induced HER3 ubiquitination and degradation in cancer cells, we analyzed by western blotting JNK1/2 (at Thr183/Tyr185) and ITCH (at Thr222) phosphorylation in BxPC3 (Figure 7A), DU145 (Figure 7B) and MDA-MB468 (Supplementary Figure S7) cancer cells following incubation with 9F7-F11 or/and NRG-1 $\beta$, or medium alone (control). Compared to control, in 9F7-F11-treated BxPC3 cells (Figure 7A), JNK1/2 phosphorylation was induced after $10 \mathrm{~min}$ of incubation $(\mathrm{SI}=4)$ and was followed by maximal and sustained ITCH phosphorylation on Thr222 (SI = 5) after 30 min of incubation and up to the end of the experiment ( $2 \mathrm{hr}$ ). This effect was stronger in DU145 cells (Figure 7B) than in BxPC3 cells (Figure 7A). JNK1/2 expression and phosphorylation were not modified by irrelevant antibody Px (Supplementary Figure S1). Similar results were obtained when cells were stimulated with NRG1- $\beta$. ITCH protein level progressively decreased, suggesting that following its activation, ITCH is degraded, in accordance with previous work demonstrating that activated ITCH auto-ubiquitinates through lysine linkage to induce polyubiquitination of its substrates [40]. Finally, JNK inhibitor SP600125 blocked 9F7-F11-mediated JNK1/2 and ITCH phosphorylation, together with HER3 degradation (Supplementary Figure S8), without modifying 9F7-F11induced inhibition of HER3 signalling. JNK1/2 blockade by SP600125 in NRG1- $\beta$-stimulated cells also abrogated ITCH activation and HER3 degradation, and slightly favored NRG1- $\beta$-induced HER3 signalling.

\section{The anti-HER3 antibody 9F7-F11 induces USP8 and USP9X expression, leading to ITCH stabilization}

USP8 and USP9X deubiquitinate ITCH to induce ubiquitination and degradation of the anti-apoptotic protein c-FLIP, leading to apoptosis in glioblastoma [45], or to anoikis in pancreatic ductal adenocarcinoma [46]. ITCH is stabilized upon interaction with USP9X [47]. To determine whether USP8 and/or USP9X stabilizes ITCH in 9F7-F11-treated cells, we analyzed USP8 and USP9X protein level in BxPC3 (Figure 8A) and DU145 (Figure 8B) cells. After 30 min incubation with 9F7-F11 in both cell lines, USP8 and USP9X expression was maximally increased by about 4-fold compared to cells with medium alone whereas control antibody Px did not modify expression (Supplementary Figure S1). The temporal kinetics of USP8/USP9X expression was comparable with that of ITCH in 9F7-F11-treated BxPC3 (Figure 8A) and DU145 (Figure 8B) cells. This suggests that USP8 and USP9X might be involved in controlling ITCH stability during 9F7-F11-induced HER3 ubiquitination and degradation. Similar results, but with a slower and longer USP8 and USP9X up-regulation, were obtained when BxPC3 or DU145 cells were stimulated by NRG-1 $\beta$. In this case, USP8 expression was maximal after $2 \mathrm{hr}$ of NRG-1 $\beta$ incubation, in close correlation with ITCH stabilization. The better correlation between ITCH and USP8 expression kinetics suggests that USP8 could be more efficient in stabilizing ITCH than USP9X. Nrdp1 activates NRG-1 $\beta$-induced HER3 degradation [32] and USP8 prevents Nrdp1 auto-ubiquitination [48], with a strong correlation between USP8 expression and Nrdp1 stabilization [36]. However, we found that Nrdp1 was not up-regulated, demonstrating the absence of correlation between USP8 over-expression and Nrdp1 stabilization in 9F7-F11-treated BxPC3 (Figure 8A) and DU145 (Figure 8B) cells. This confirms that Nrdp1 is not involved in 9F7-F11-induced HER3 degradation.

\section{USP8 or USP9X silencing inhibits ITCH- mediated HER3 degradation induced by the anti-HER3 antibody 9F7-F11}

It was previously reported that USP9X knockdown induces ITCH down-regulation in BxPC3 cells cultured in agar suspension, but not in monolayer [49]. To investigate USP9X and USP8 role in ITCH protein stabilization, we silenced the USP8 or/and USP9X genes by siRNA transfection in BxPC3 (Figure 9A) and DU145 (Figure 9B) cells for $72 \mathrm{hr}$. USP8 or USP9X silencing increased HER3 protein level in basal conditions (medium alone) in BxPC3 cells, suggesting that each deubiquitinase promotes basal HER3 degradation by stabilizing ITCH, as proposed for USP8 [36]. Conversely, ITCH expression was not modified, suggesting that when USP8 is downregulated, USP9X maintains ITCH protein stability, and vice versa. Only concomitant silencing of USP8 and USP9X reduced ITCH expression, leading to loss of JNKmediated ITCH phosphorylation on Thr222. Accordingly, 9F7-F11-induced HER3 degradation was inhibited in BxPC3 or DU145 cells in which both deubiquitinases 
A
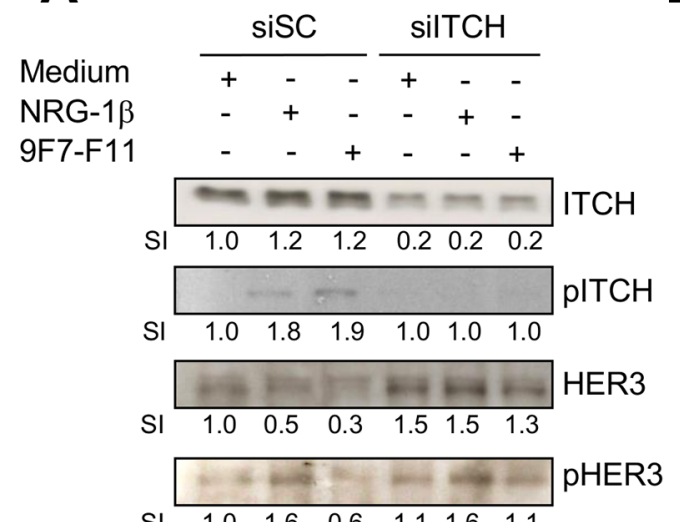

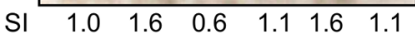
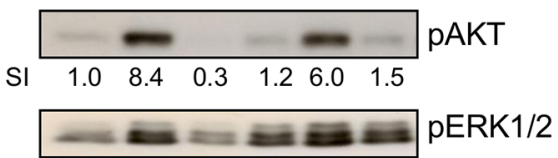

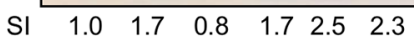

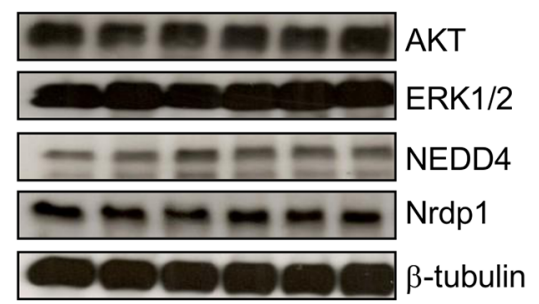

B

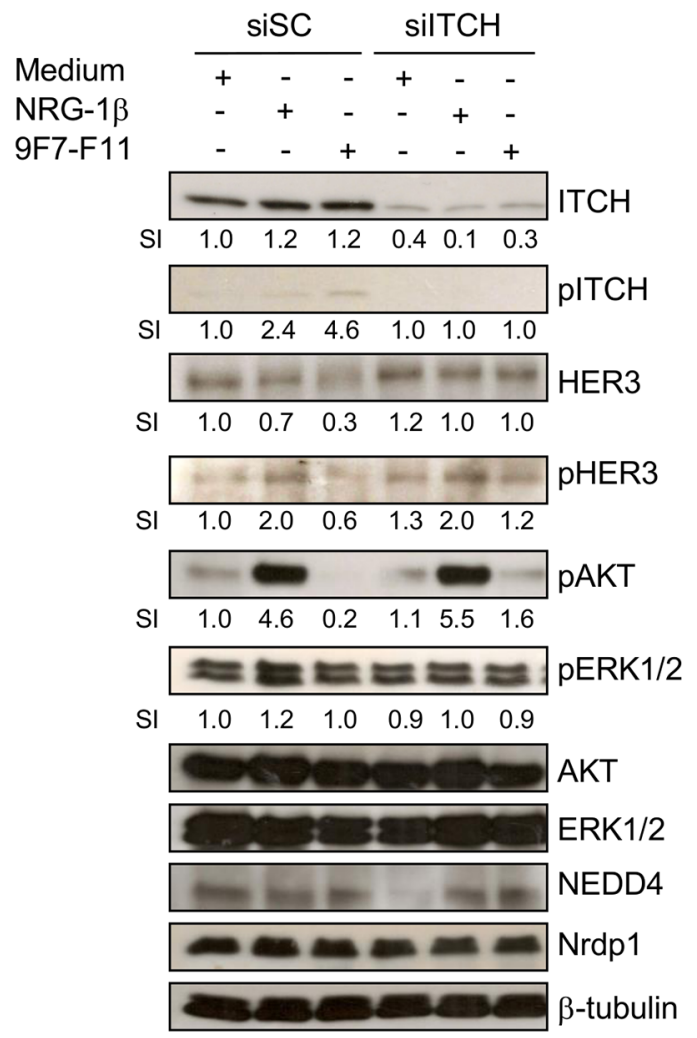

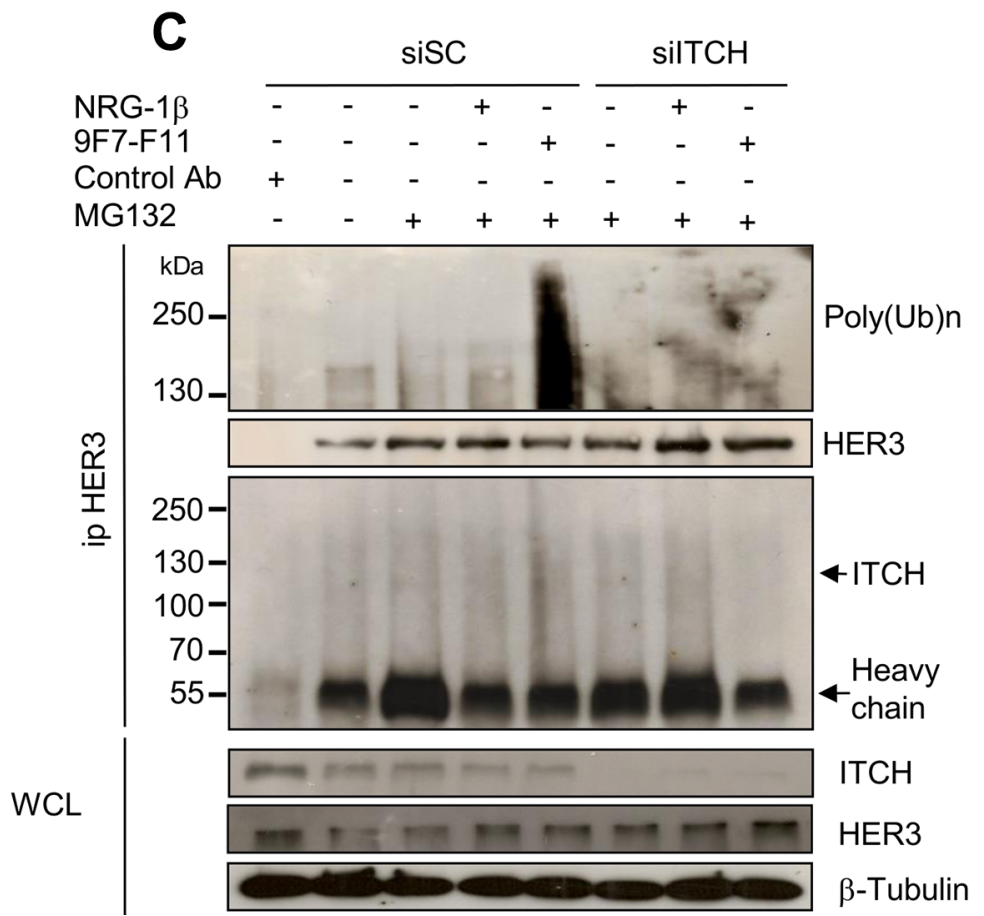

Figure 6: ITCH silencing inhibits 9F7-F11-mediated HER3 degradation and ubiquitination in cancer cells. Pancreatic BxPC3 (A) and prostatic DU145 (B) cancer cells were transfected with $10 \mathrm{nM}$ Scramble Control siRNA (siSC) or the anti-ITCH/AIP4 siRNA (siITCH) for $72 \mathrm{hr}$, serum-starved and then incubated with $50 \mu \mathrm{g} / \mathrm{mL}$ 9F7-F11 or with $100 \mathrm{ng} / \mathrm{mL}$ NRG-1 $\beta$ for $4 \mathrm{hr}$. ITCH, HER3, AKT, ERK1/2, NEDD4 and Nrdp1 protein expression and ITCH, HER3, AKT and ERK1/2 phosphorylation were assessed in whole cell lysates (WCL) by western blotting. Band signal intensity (SI) was quantified with ImageJ, and $\beta$-tubulin was used as loading control. (C) BxPC3 cells were transfected with $10 \mathrm{nM}$ siSC or siITCH for $72 \mathrm{hr}$, and then pre-incubated with $10 \mu \mathrm{M}$ MG132 for $4 \mathrm{hr}$ before addition of 9F7-F11 or NRG1- $\beta$ for $4 \mathrm{hr}$. After immunoprecipitation with HER Ab, the HER3 ubiquitination status was analyzed by western blotting with a specific poly-ubiquitin chain antibody. HER3 and ITCH proteins were also detected by using specific antibodies. 
were silenced. This suggests that USP8 and USP9X act concomitantly to favor ITCH stability, leading to 9F7-F11induced HER3 ubiquitination and degradation. In contrast USP8 and/or USP9X silencing did not modify 9F7-F11induced inhibition of HER3 and AKT phosphorylation (Supplementary Figure S9).

\section{DISCUSSION}

There are currently intense efforts towards the development of anti-HER3 antibodies for cancer treatment $[8,9,50]$. Most of these antibodies act by blocking the binding site for NRG-1 $\beta$ [10-12]. Targeting EGFR or HER2 by antibody-mediated ubiquitination and degradation $[24,25,27-29,51]$ is one attractive way to improve therapeutic benefit in patients. Such mechanism has been also proposed for antibodies against HER3 [15, 50, 52, 53] or IGFR1 [54]. Pre-clinical studies using anti-HER3 antibodies clearly identified receptor degradation as a marker of drug efficacy [55]. A mixture of anti-EGFR monoclonal antibodies that target different EGFR epitopes and increase
EGFR ubiquitination and degradation in a CBL-independent manner led to improved efficacy of anti-EGFR therapy [24]. Finally, small molecules, such as the anti-anginal drug perhexilline, promote HER3 internalization and further ubiquitination, leading to inhibition of tumor growth [56].

In this study, we demonstrate that the therapeutic anti-HER3 antibody 9F7-F11 [15] induces HER3 ubiquitination and degradation through JNK1/2-dependent activation of the HECT E3 ubiquitin ligase ITCH/AIP4. This effect is co-activated by the deubiquitinases USP8 and USP9X. The AKT kinase has been previously shown to decrease USP8 function by increasing USP8 ubiquitination and decreasing active steady-state USP8 level [45]. 9F7-F11-induced inhibition of AKT phosphorylation [15] could relieve the blocking effect of AKT on USP8/ USP9X function, allowing USP8/USP9X-mediated ITCH deubiquitination and stabilization. ITCH can induce ubiquitination of multiple proteins, including p63 and p73 [57, 58] and HER4 [22, 37], by interacting directly through its WW domains with a PPXY binding motif in the C-terminal tail of HER4 [22]. We identified this
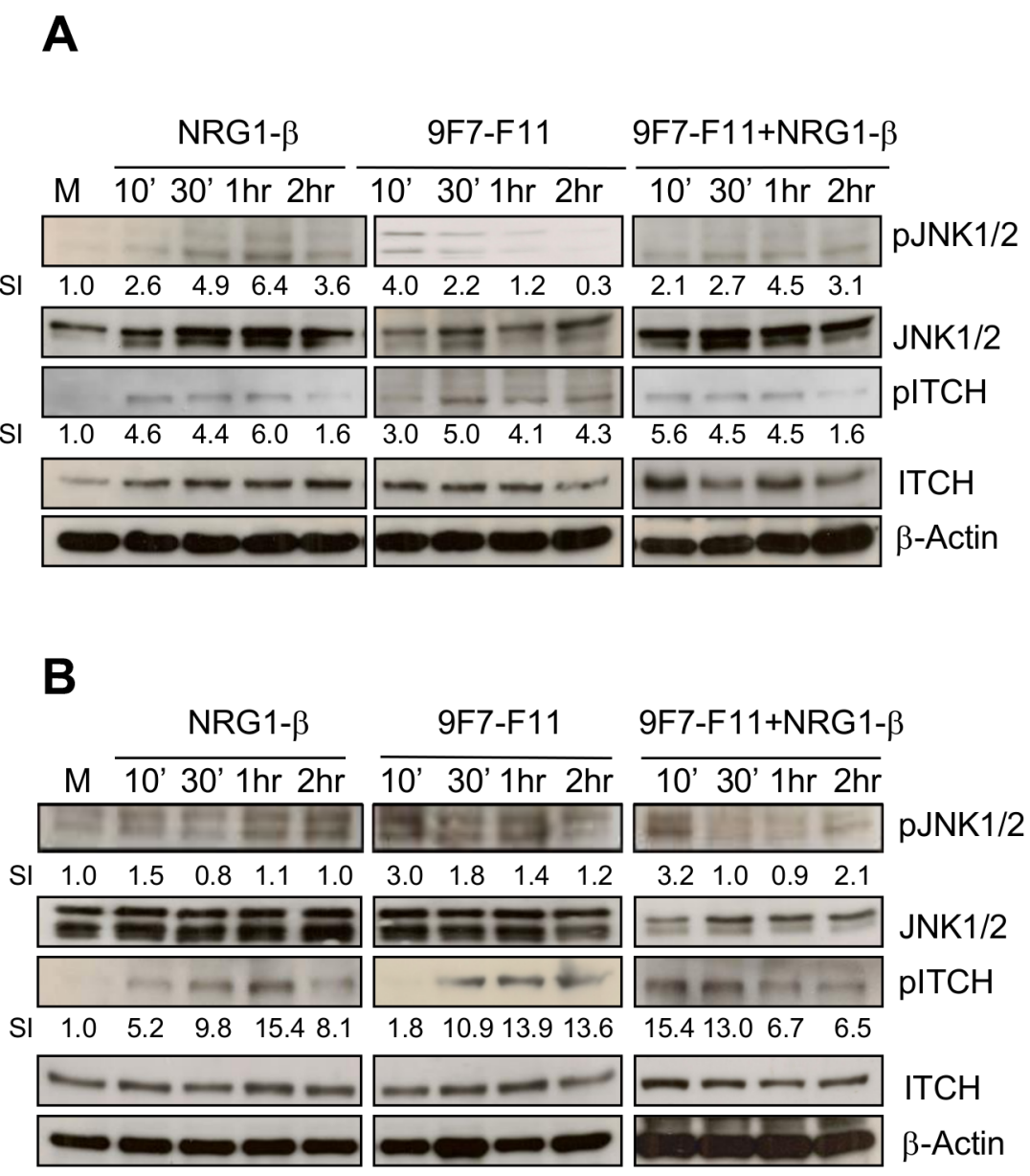

Figure 7: The anti-HER3 antibody 9F7-F11 induces JNK1/2 phosphorylation leading to ITCH activation in cancer cells. Serum-starved cells from BxPC3 (A) and DU145 (B) cell lines were incubated with $100 \mathrm{ng} / \mathrm{mL}$ NRG-1 $\beta$ and/or $50 \mu \mathrm{g} / \mathrm{mL} 9$ F7-F11 for the indicated times. JNK1/2 and ITCH protein expression and their phosphorylation status were assessed in whole cell extracts by western blotting using the appropriate antibodies. Band signal intensity (SI) was quantified with ImageJ and $\beta$-actin was used as loading control. 
specific motif in the C-terminal tail of HER3 by sequence homology with HER4. This motif is also used for binding to NEDD4 [33], another HECT E3 ubiquitin ligase. Multiple E3 ubiquitin ligases can interact and regulate one substrate, depending on the cell context and the nature of the targeted protein. For example, in the EGFR family, HER4 is targeted by the two HECT E3 ubiquitin ligases WWP1 and ITCH to mediate its proteasomal and lysosomal degradation [21, 22]. Similarly, HER3 can be ubiquitinated by the RING E3 ubiquitin ligase Nrdp1 and also by NEDD4, leading to HER3 proteasome degradation [31-33]. In these cases, Nrdp1 and NEDD4 are only involved in HER3 degradation in basal conditions or after NRG-1 $\beta$ stimulation, but not in drug-induced HER3 degradation. This is in agreement with a previous report showing that NEDD4 participates in the basal ubiquitination and degradation of IGF-1R [59], but not following incubation with the specific antibody $\mathrm{h} 7 \mathrm{C} 10$ [54]. Conversely, ITCH/AIP4 binds to and ubiquitinates
HER3 upon incubation with the therapeutic antibody 9F7-F11, without affecting HER3 degradation in basal conditions. Nrdp1 interacts with HER3 juxtamembrane domain or kinase domain [60], whereas NEDD4 binds to the same motif [33] used by ITCH in HER3 C-terminal tail. The activity of these two ubiquitin ligases is probably regulated by the cell context (basal conditions vs druginduced). This could explain why NEDD4 needs to be inhibited to sensitize cancer cells to anti-HER3 adjuvant therapy [33], whereas ITCH must be maintained to activate the drug biological effects, as we observed with the anti-HER3 antibody 9F7-F11. Therefore, compounds that indirectly increase ITCH expression, such as DNA methylase inhibitors that promote USP9X expression [46], could be beneficial.

Further studies are needed to understand first how 9F7-F11 induces JNK1/2 activation, leading to ITCH activation, and second how 9F7-F11 induces HER3 internalization and intracellular trafficking. 9F7-

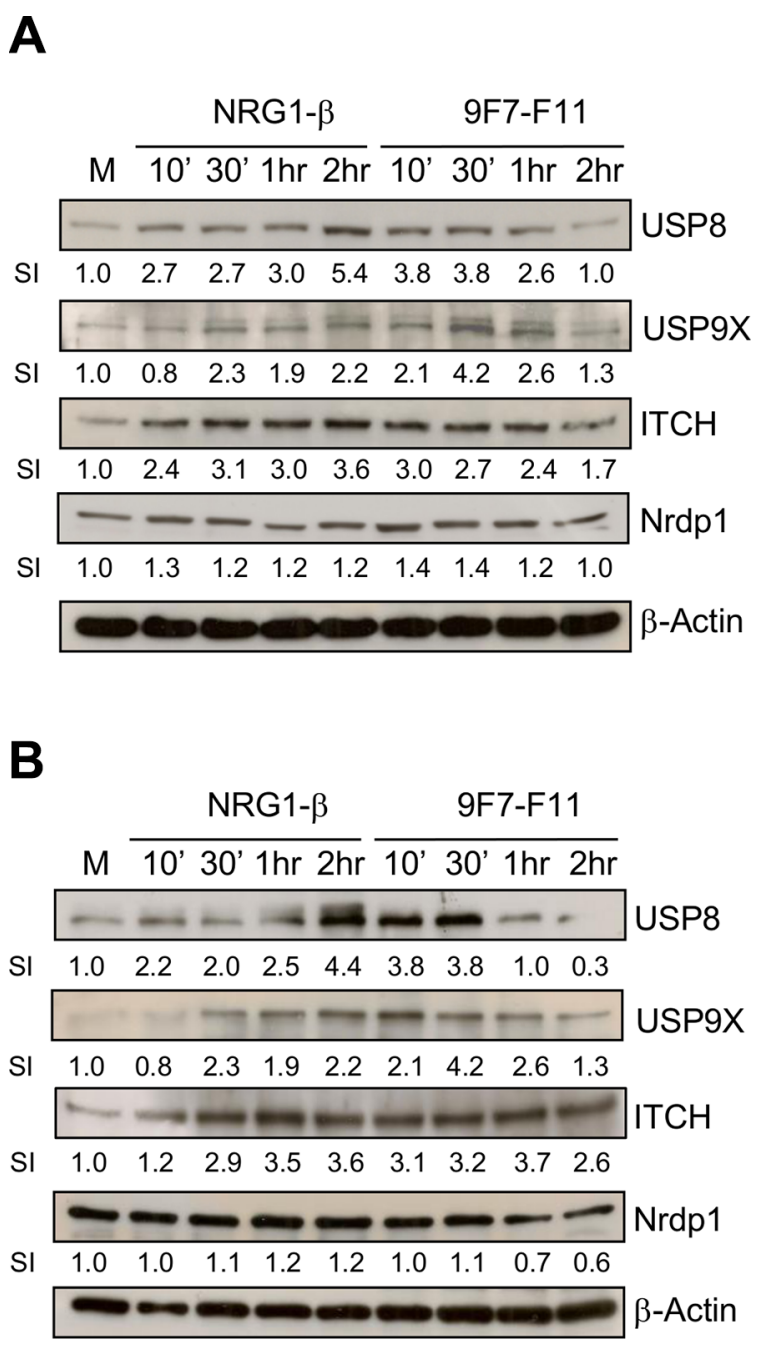

Figure 8: The anti-HER3 antibody 9F7-F11 increases USP8 and USP9X expression, leading to ITCH stabilization cancer cells. Serum-starved cells from BxPC3 (A) and DU145 (B) cell lines were incubated with $100 \mathrm{ng} / \mathrm{mL} \mathrm{NRG-1 \beta} \mathrm{or} 50 \mu \mathrm{g} / \mathrm{mL}$ 9F7-F11 for the indicated times. USP8, USP9X, ITCH and Nrdp1 protein expression were assessed in whole cell extracts by western blotting using the appropriate antibodies. Band signal intensity (SI) was quantified with ImageJ and $\beta$-actin was used as loading control. 
A
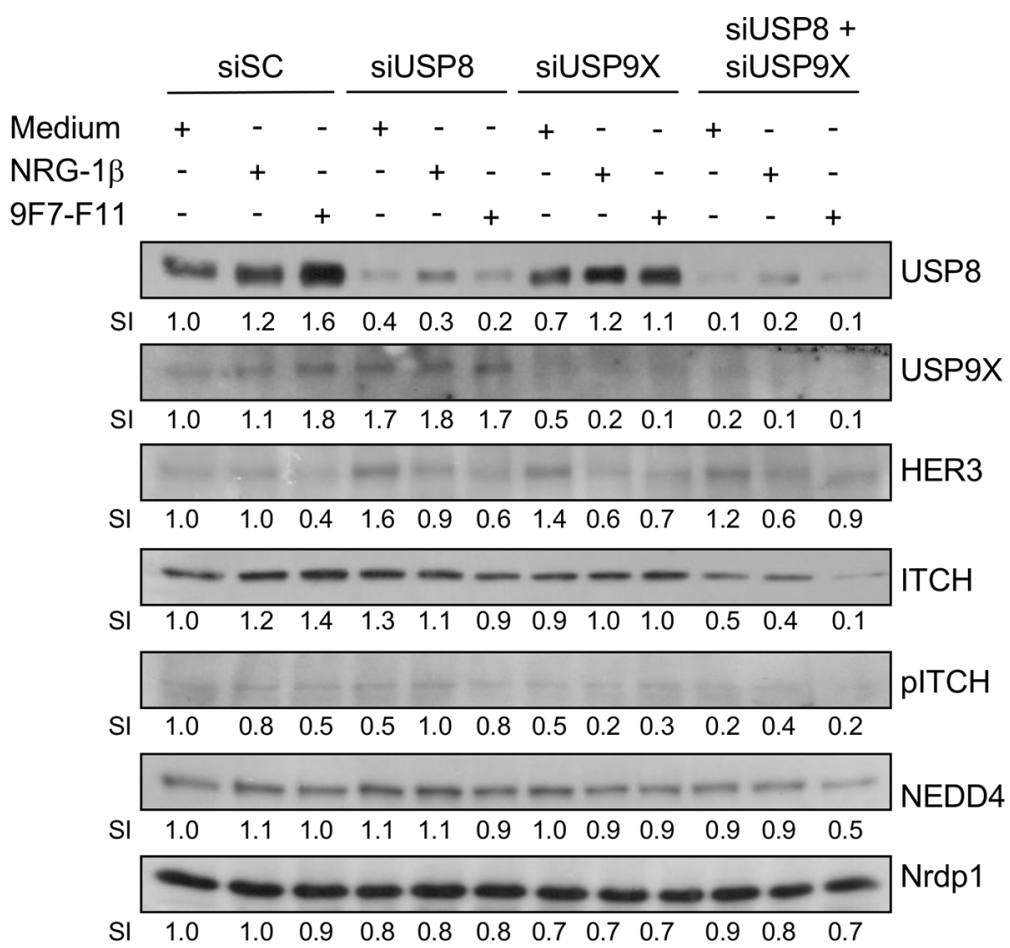

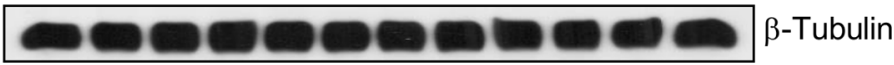

B

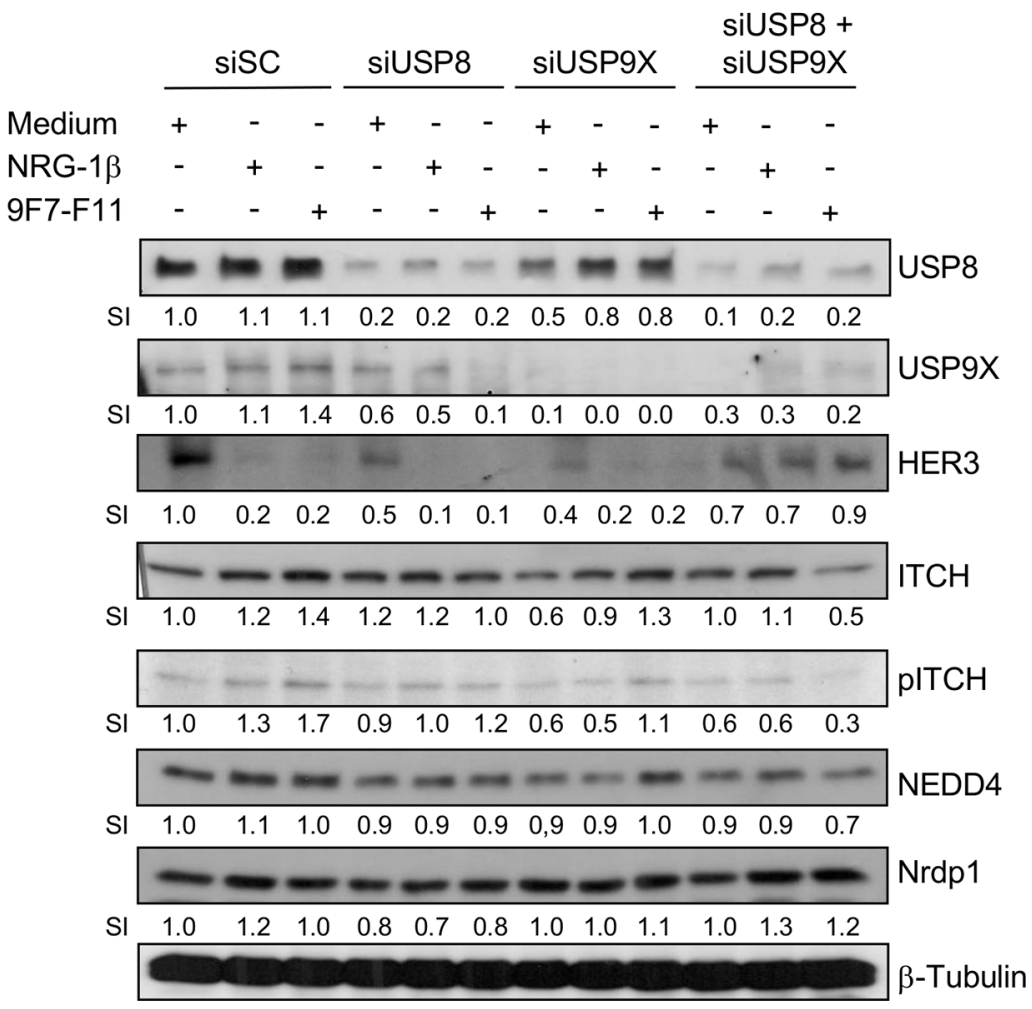

Figure 9: Simultaneous USP8/USP9X silencing inhibits ITCH-mediated HER3 degradation induced by 9F7-F11 in cancer cells. BxPC3 (A) and DU145 (B) cancer cells were transfected with $10 \mathrm{nM}$ scramble control siRNA (siSC), or anti-USP8 (siUSP8) or/and anti-USP9X siRNA (siUSP9X) for $72 \mathrm{hr}$. Transfected cells were then serum-starved and incubated with $50 \mu \mathrm{g} / \mathrm{mL}$ 9F7-F11 antibody or with $100 \mathrm{ng} / \mathrm{mL}$ NRG1- $\beta$ for $4 \mathrm{hr}$. USP8, USP9X, HER3, ITCH, NEDD4 and Nrdp1 expression were assessed in whole cell extracts by western blotting. ITCH phosphorylation at Thr222 was also evaluated using a specific pT222 antibody. $\beta$-tubulin was used as loading control. Band signal intensity (SI) was quantified with ImageJ. 
F11 antibody induces caspase-dependent cell apoptosis [15; unpublished results]. Oxidative stress is often associated with apoptosis and JNKs respond to cellular stress signals by phosphorylation. Therapeutic antibodies have been demonstrated to induce cell apoptosis together with reactive oxygen species accumulation, leading to JNK activation and phosphorylation $[61,62]$. Thus we hypothesize that initiation of 9F7-F11-induced cell apoptosis could induce sustained stress generation, leading to $\mathrm{JNK}$ activation. ITCH is involved in protein trafficking by interacting with proteins of the ESCRT 0 complex, such as STAM and Hrs [63, 64], that could participate to antibody-induced HER3 degradation. The negative regulation of HER3 by 9F7-F11 via the ITCH E3 ligase has significant implications in our understanding of HER3 role in cancer biology, notably in pancreatic ductal adenocarcinoma. We demonstrate that the expression of the deubiquitinase USP9X, which activates ITCH stability, is increased in 9F7-F11-treated pancreatic cancer cells. Loss of USP9X expression leads to ITCH down-regulation and consequently could induce resistance to anoikis [46] and promote metastasis formation. Tumors with undetectable USP9X (13.6\%) and ITCH (30.5\%) have a worse prognosis [46]. ITCH down-regulation (and consequently reduction of HER3 ubiquitination and degradation) could maintain high HER3 expression in pancreatic ductal adenocarcinoma, driving metastasis formation via HER3 signaling. ITCHmediated HER3 ubiquitination and degradation by 9F7-F11 could partly explain why this therapeutic antibody reduced tumor xenograft growth in nude mice $[15,65]$. In addition, we can speculate that ITCH expression, and more broadly HER3 degradation, could be used as markers of response to anti-HER3 antibody targeted therapy, particularly in pancreatic and prostate cancer.

\section{MATERIALS AND METHODS}

\section{Cells, antibodies and other reagents}

The human pancreatic BxPC3, breast MDA-MB468 and prostate DU145 cancer cell lines were obtained from the American Type Culture collection (ATCC) (Rockville, MD). They all expressed the HER3 receptor (around 10,000 receptors/cell as quantified by flow cytometry) but not HER4. All cell lines were free of mycoplasma contamination, which was determined by the MycoAlert ${ }^{\mathrm{TM}}$ Detection Kit (Lonza, Switzerland). BxPC3 cells were cultured in Roswell Park Memorial Institute medium (RPMI) 1640. MDA-MB468 and DU145 cells were cultured in Dulbecco's modified Eagle's medium (DMEM). The culture media were supplemented as recommended by ATCC, usually with 10\% fetal calf serum (FCS) and with penicillin and streptomycin (complete medium). All culture media and supplements were purchased from Life Technologies Inc. (Gibco BRL, Gaithersburg, MD). All cell lines were grown at $37^{\circ} \mathrm{C}$ in a humidified atmosphere with $5 \% \mathrm{CO}_{2}$ and medium was replaced twice a week.
For western blotting, rabbit monoclonal antibodies against phospho-HER3 (Y1289), HER3, AKT, phospho-AKT (S473), ERK1/2 and phospho-ERK1/2 (Thr202/204), JNK1/2 and phospho-JNK1/2 (Thr183/Tyr185), USP9X, beta-actin and beta-tubulin were from Cell Signaling Technology (Danvers, MA). The mouse monoclonal antibody against ITCH (ref. 611199) was from BD Biosciences (San José, CA). The rabbit polyclonal antibodies against HER3 (C17), USP8 and USP9X were from Santa Cruz Biotechnology (Santa Cruz, CA). The rabbit polyclonal antibody against Nrdp1 was from Bethyl Laboratories (Montgomery, TX). The peroxidase-conjugated rabbit polyclonal anti-HA antibody, JNK inhibitor SP600125 (1,9-pyrazoloanthrone), MG132 and chloroquine were from Sigma-Aldrich (St Louis, MO). For detection of activated JNK and ITCH, we used a rabbit anti-phospho-JNK1/2 (Thr183/Tyr185) (clone 81E11) and an anti-phospho ITCH (Thr222) antibody (Millipore, Billerica, MA). We immunoprecipitated HER3 with the mouse monoclonal anti-HER3 antibody 2F12 (Millipore) against the epitope 1295-1323 in HER3 C-terminal domain. Human recombinant NRG-1 $\beta$ extracellular domain (ECD) was from RD Systems (Minneapolis, MN) and was used at $100 \mathrm{ng} / \mathrm{mL}$. The normal control IgG antibody used for co-immunoprecipitation was obtained from Santa Cruz Biotechnology. The irrelevant control antibody Px, used for cell signaling experiments, is an $\mathrm{IgG}_{1}$ monoclonal antibody that was purified from the mouse myeloma cell line MOPC21. The mouse anti-HER3 therapeutic antibody 9F7-F11 was produced in our laboratory and used at $50 \mu \mathrm{g} / \mathrm{mL}$ [15].

\section{Transfection, overexpression and siRNA knockdown}

For transient overexpression, the pcDNA-N4PB1GFP vector (human full-length N4BP1 cDNA fused to GFP), the pcDNA-Myc-ITCHwt vector (full-length wild type ITCH cDNA fused to the Myc tag) and the pcDNAHA-Ub vector (full-length linear ubiquitin fused to the HA tag) were generated by Gerry Melino. $2 \times 10^{6}$ cells were plated in $10 \mathrm{~cm}$-diameter dishes with complete RPMI or DMEM medium. When they reached 50-70\% confluence, cells were transfected using Jet-PEITM from Polyplus (New-York, NY) and $2 \mu \mathrm{g} /$ plate of each vector for $24 \mathrm{hr}$. For siRNA-mediated knockdown, $2 \times 10^{6}$ BxPC3 or DU145 cells were plated in $10 \mathrm{~cm}$-dishes with RMPI medium without antibiotics until $50 \%$ confluence (about $24 \mathrm{hr}$ ). Cells were then transfected with $10 \mathrm{nM}$ of pools of four specific different siRNAs against human ITCH, Nrdp1, NEDD4, USP8, USP9X respectively, or scramble control (ON-TARGETplus SMART pool, Dharmacon, Germany) in OptiMEM medium using Oligofectamine or Interferin ${ }^{\mathrm{TM}}$ (Life Technologies, Carlsbad, CA). After $4 \mathrm{hr}$ of transfection, medium was replaced by RPMI for another $72 \mathrm{hr}$ before using the cells for experiments. 


\section{Cell lysis and immunoprecipitation}

Cells were lysed in CHAPS buffer (Sigma-Aldrich) containing the protease inhibitor cocktail V (Calbiochem, Billerica, MA) and the phosphatase inhibitor cocktail II (Sigma-Aldrich). HER3 immunoprecipitation was performed by incubating $2 \mathrm{mg}$ of cell lysate with $2 \mu \mathrm{g}$ of the anti-HER3 antibody $2 \mathrm{~F} 12$, which recognizes the HER3 intracellular C-terminal tail, at $4^{\circ} \mathrm{C}$ for $6 \mathrm{hr}$, followed by overnight incubation with $20 \mu \mathrm{l}$ of protein $\mathrm{A} / \mathrm{G}$ agarose beads (Santa Cruz Biotechnology) or with magnetic beads (Dynabeads ${ }^{\mathrm{TM}}$; Life Technologies) at $4^{\circ} \mathrm{C}$ under agitation. Samples were washed five times with $400 \mu$ CHAPS buffer, re-suspended in $100 \mu \mathrm{l}$ of 2X SDS Laemmli buffer and heated at $90^{\circ} \mathrm{C}$ for $10 \mathrm{~min}$ before electrophoresis. In each case, no HER 3 protein was immunoprecipitated with beads alone or with normal control IgG antibody.

\section{Western blotting}

$2 \times 10^{6}$ cells/dish were cultured at $37^{\circ} \mathrm{C}$ for $24 \mathrm{hr}$. After serum starvation in RPMI with antibiotics and $1 \%$ FCS for $24 \mathrm{hr}$, cells were incubated with various compounds. Treated cells were washed, scraped and lysed with CHAPS buffer (Sigma-Aldrich), as indicated above. After $5 \mathrm{hr}$ of incubation at $4^{\circ} \mathrm{C}$, the insoluble fraction was eliminated by centrifugation (13000 rpm, $10 \mathrm{~min})$ and protein concentration in cell lysates was determined by the BCA assay. $200 \mu \mathrm{g}$ of protein lysates were directly mixed with Laemmli buffer and heated at $95^{\circ} \mathrm{C}$ for $5 \mathrm{~min}$. After SDS-PAGE in reducing conditions, proteins were transferred to polyvinylidene difluoride membranes (Millipore) that were then saturated in TBS-Tween buffer $(25 \mathrm{mM}$ Tris $\mathrm{pH}$ $7.4,150 \mathrm{mM} \mathrm{NaCl}, 0.1 \%$ Tween) containing $5 \%$ non-fat dry milk at $25^{\circ} \mathrm{C}$ for $1 \mathrm{hr}$. Membranes were then incubated with the appropriate dilution of primary antibodies in TBSTween $/ 5 \%$ BSA buffer at $4^{\circ} \mathrm{C}$ for $18 \mathrm{hr}$. After two washes in TBS-Tween buffer, peroxidase-conjugated rabbit, goat or mouse polyclonal secondary antibodies (Sigma-Aldrich) were added, as appropriate, in TBS-Tween buffer containing $5 \%$ non-fat dry milk at $25^{\circ} \mathrm{C}$ for $1 \mathrm{hr}$. After three washes in TBS-Tween buffer, antibody binding was visualized using a chemiluminescent substrate (Western Lightning Plus-ECL, Perkin Elmer, Waltham, MA). Quantification was done using Image J. The signal intensity (SI) of each protein detected in non-treated cells served as the reference for estimating the expression changes $(\mathrm{SI}>1$ or $\mathrm{SI}<1$ ) of a given protein.

\section{ACKNOWLEDGMENTS AND FUNDING}

We thank G. Heintz and S. Bousquié for excellent technical assistance. This work was supported by the program "Investissement d'Avenir" (grant agreement: Labex MabImprove, ANR-10-LABX-53-01) and by the grant AAP13 "Fonds Unique Interministeriel" FUI UmAbHER3 F120402M.

\section{CONFLICTS OF INTEREST}

The authors declare no conflicts of interest.

\section{REFERENCES}

1. Gaborit N, Lindzen M, Yarden Y. Emerging anti-cancer antibodies and combination therapies targeting HER3/ ErbB3. Hum Vaccin Immunother. 2016; 12:576-593.

2. Friess H, Yamanaka Y, Kobrin MS, Do DA, Buchler MW, Korc M. Enhanced erbB-3 expression in human pancreatic cancer correlates with tumor progression. Clin Cancer Res. 1995; 1:1413-1420.

3. Hayashi M, Inokuchi M, Takagi Y, Yamada H, Kojima K, Kumagai J, Kawano T, Sugihara K. High expression of HER3 is associated with a decreased survival in gastric cancer. Clin Cancer Res. 2008; 14:7843-7849.

4. Naidu R, Yadav M, Nair S, Kutty MK. Expression of c-erbB3 protein in primary breast carcinomas. Br J Cancer. 1998; 78:1385-1390.

5. Reschke M, Mihic-Probst D, van der Horst EH, Knyazev P, Wild PJ, Hutterer M, Meyer S, Dummer R, Moch H, Ullrich A. HER3 is a determinant for poor prognosis in melanoma. Clin Cancer Res. 2008; 14:5188-5197.

6. Takikita M, Xie R, Chung JY, Cho H, Ylaya K, Hong SM, Moskaluk CA, Hewitt SM. Membranous expression of Her3 is associated with a decreased survival in head and neck squamous cell carcinoma. J Transl Med. 2011; 9:126-136.

7. Tanner B, Hasenclever D, Stern K, Schormann W, Bezler M, Hermes M, Brulport M, Bauer A, Schiffer IB, Gebhard S, Schmidt M, Steiner E, Sehouli H et al. ErbB-3 predicts survival in ovarian cancer. J Clin Oncol. 2006; 24:4317-4323.

8. Schaefer G, Haber L, Crocker LM, Shia S, Shao L, Dowbenko D, Totpal K, Wong A, Lee CV, Stawicki S, Clark R, Fields C, et al. A two-in-one antibody against HER3 and EGFR has superior inhibitory activity compared with monospecific antibodies. Cancer Cell. 2011; 20:472-486.

9. Schoeberl B, Pace EA, Fitzgerald JB, Harms BD, Xu L, Nie L, Linggi B, Kalra A, Paragas V, Bukhalid R, Grantcharova V, Kohli N, West KA, et al. Therapeutically targeting ErbB3: a key node in ligand-induced activation of the ErbB receptor-PI3K axis. Sci Signal. 2009; 2:ra31.

10. Beji A, Horst D, Engel J, Kirchner T, Ullrich A. Toward the prognostic significance and therapeutic potential of HER3 receptor tyrosine kinase in human colon cancer. Clin Cancer Res. 2012; 18:956-968.

11. Blackburn E, Zona S, Murphy ML, Brown IR, Chan SK, Gullick WJ. A monoclonal antibody to the human HER3 receptor inhibits Neuregulin 1-beta binding and co-operates with Herceptin in inhibiting the growth of breast cancer derived cell lines. Breast Cancer Res Treat. 2012; 134:53-59.

12. Schoeberl B, Faber AC, Li D, Liang MC, Crosby K, Onsum M, Burenkova O, Pace E, Walton Z, Nie L, 
Fulgham A, Song Y, Nielsen UB, et al. An ErbB3 antibody, MM-121, is active in cancers with ligand-dependent activation. Cancer Res. 2010; 70:2485-2494.

13. Campbell MR, Amin D, Moasser MM. HER3 comes of age: new insights into its functions and role in signalling, tumor biology, and cancer therapy. Clin Cancer Res. 2010; 16:1373-1383.

14. Sheng Q, Liu X, Fleming E, Yuan K, Piao H, Chen J, Moustafa Z, Thomas RK, Greulich H, Schinzel A, Zaghlul S, Batt D, Ettenberg S, et al. An activated ErbB3/ NRG1 autocrine loop supports in vivo proliferation in ovarian cancer cells. Cancer Cell. 2010; 17:298-310.

15. Lazrek Y, Dubreuil O, Garambois V, Gaborit N, Larbouret C, Le Clorennec C, Thomas G, Leconet W, Jarlier M, Pugnière M, Vié N, Robert B, Monnet $\mathrm{C}$, et al. Anti-HER3 domain 1 and 3 antibodies reduce tumor growth by hindering HER2/HER3 dimerization and AKT-induced MDM2, XIAP, and FoxO1 phosphorylation. Neoplasia. 2013; 15:335-347.

16. Lipkowitz $\mathrm{S}$. The role of the ubiquitination-proteasome pathway in breast cancer: ubiquitin mediated degradation of growth factor receptors in the pathogenesis and treatment of cancer. Breast Cancer Res. 2003; 5:8-15.

17. Weissman AM, Shabek N, Ciechanover A. The predator becomes the prey: regulating the ubiquitin system by ubiquitylation and degradation. Nat Rev Mol Cell Biol. 2011; 12:605-620.

18. Carraway KL, 3rd. E3 ubiquitin ligases in ErbB receptor quantity control. Semin Cell Dev Biol. 2010; 21:936-943.

19. Thien CB, Langdon WY. c-Cbl and Cbl-b ubiquitin ligases: substrate diversity and the negative regulation of signalling responses. Biochem J. 2005; 391:153-166.

20. Xu W, Marcu M, Yuan X, Mimnaugh E, Patterson C, Neckers L. Chaperone-dependent E3 ubiquitin ligase CHIP mediates a degradative pathway for c-ErbB2/Neu. Proc Natl Acad Sci USA. 2002; 99:12847-12852.

21. Feng SM, Muraoka-Cook RS, Hunter D, Sandahl MA, Caskey LS, Miyazawa K, Atfi A, Earp HS 3rd. The E3 ubiquitin ligase WWP1 selectively targets HER4 and its proteolytically derived signalling isoforms for degradation. Mol Cell Biol. 2009; 29:892-906.

22. Omerovic J, Santangelo L, Puggioni EM, Marrocco J, Dall'Armi C, Palumbo C, Belleudi F, Di Marcotullio L, Frati L, Torrisi MR, Cesareni G, Gulino A, Alimandi M. The E3 ligase Aip4/Itch ubiquitinates and targets ErbB-4 for degradation. Faseb J. 2007; 21:2849-2862.

23. Wheeler DL, Huang S, Kruser TJ, Nechrebecki MM, Armstrong EA, Benavente S, Gondi V, Hsu KT, Harari PM. Mechanisms of acquired resistance to cetuximab: role of HER (ErbB) family members. Oncogene. 2008; 27:3944-3956.

24. Ferraro DA, Gaborit N, Maron R, Cohen-Dvashi H, Porat Z, Pareja F, Lavi S, Lindzen M, Ben-Chetrit N, Sela M, Yarden Y. Inhibition of triple-negative breast cancer models by combinations of antibodies to EGFR. Proc Natl Acad Sci USA. 2013; 110:1815-1820.
25. Ben-Kasus T, Schechter B, Lavi S, Yarden Y, Sela M. Persistent elimination of ErbB-2/HER2-overexpressing tumors using combinations of monoclonal antibodies: relevance of receptor endocytosis. Proc Natl Acad Sci USA. 2009; 106:3294-3299.

26. Maron R, Schechter B, Mancini M, Mahlknecht G, Yarden Y, Sela M. Inhibition of pancreatic carcinoma by homo- and heterocombinations of antibodies against EGFreceptor and its kin HER2/ErbB-2. Proc Natl Acad Sci USA. 2013; 110:15389-15394.

27. Spangler JB, Neil JR, Abramovitch S, Yarden Y, White FM, Lauffenburger DA, Wittrup KD. Combination antibody treatment down-regulates epidermal growth factor receptor by inhibiting endosomal recycling. Proc Natl Acad Sci USA. 2010; 107:13252-13257.

28. Friedman LM, Rinon A, Schechter B, Lyass L, Lavi S, Bacus SS, Sela M, Yarden Y. Synergistic down-regulation of receptor tyrosine kinases by combinations of mAbs: implications for cancer immunotherapy. Proc Natl Acad Sci USA. 2005; 102:1915-1920.

29. Klapper LN, Waterman H, Sela M, Yarden Y. Tumorinhibitory antibodies to HER-2/ErbB-2 may act by recruiting $\mathrm{c}-\mathrm{Cbl}$ and enhancing ubiquitination of HER-2. Cancer Res. 2000; 60:3384-3388.

30. Lee JM, Kim B, Lee SB, Jeong Y, Oh YM, Song YJ, Jung S, Choi J, Lee S, Cheong KH, Kim DU, Park HW, Han YK et al. Cbl-independent degradation of Met: ways to avoid agonism of bivalent Met-targeting antibody. Oncogene. $2014 ; 33: 34-43$.

31. Diamonti AJ, Guy PM, Ivanof C, Wong K, Sweeney C, Carraway KL, 3rd. An RBCC protein implicated in maintenance of steady-state neuregulin receptor levels. Proc Natl Acad Sci USA. 2002; 99:2866-2871.

32. Qiu XB, Goldberg AL. Nrdp1/FLRF is a ubiquitin ligase promoting ubiquitination and degradation of the epidermal growth factor receptor family member, ErbB3. Proc Natl Acad Sci USA. 2002; 99:14843-14848.

33. Huang Z, Choi BK, Mujoo K, Fan X, Fa M, Mukherjee S, Owiti N, Zhang N, An Z. The E3 ubiquitin ligase NEDD4 negatively regulates HER3/ErbB3 level and signalling. Oncogene. 2015; 34:1105-1115.

34. Amin DN, Sergina N, Lim L, Goga A, Moasser MM. HER3 signalling is regulated through a multitude of redundant mechanisms in HER2-driven tumour cells. Biochem J. 2012; 447:417-425.

35. Wee S, Jagani Z, Xiang KX, Loo A, Dorsch M, Yao YM, Sellers WR, Lengauer C, Stegmeier F. PI3K pathway activation mediates resistance to MEK inhibitors in KRAS mutant cancers. Cancer Res. 2009; 69:4286-4293.

36. Cao Z, Wu X, Yen L, Sweeney C, Carraway KL, 3rd. Neuregulin-induced ErbB3 downregulation is mediated by a protein stability cascade involving the E3 ubiquitin ligase Nrdp1. Mol Cell Biol. 2007; 27:2180-2188.

37. Sundvall M, Korhonen A, Paatero I, Gaudio E, Melino G, Croce CM, Aqeilan RI, Elenius K. Isoform-specific 
monoubiquitination, endocytosis, and degradation of alternatively spliced ErbB4 isoforms. Proc Natl Acad Sci USA. 2008; 105:4162-4167.

38. Zeng F, Xu J, Harris RC. Nedd4 mediates ErbB4 JM-a/ CYT-1 ICD ubiquitination and degradation in MDCK II cells. Faseb J. 2009; 23:1935-1945.

39. Gallagher E, Gao M, Liu YC, Karin M. Activation of the E3 ubiquitin ligase Itch through a phosphorylation-induced conformational change. Proc Natl Acad Sci USA. 2006; 103:1717-1722.

40. Scialpi F, Malatesta M, Peschiaroli A, Rossi M, Melino G, Bernassola F. Itch self-polyubiquitylation occurs through lysine-63 linkages. Biochem Pharmacol. 2008; 76:1515-1521.

41. Oberst A, Malatesta M, Aqeilan RI, Rossi M, Salomoni P, Murillas R, Sharma P, Kuehn MR, Oren M, Croce CM, Bernassola F, Melino G. The Nedd4-binding partner 1 (N4BP1) protein is an inhibitor of the E3 ligase Itch. Proc Natl Acad Sci USA. 2007; 104:11280-11285.

42. Riling C, Kamadurai H, Kumar S, O’Leary CE, Wu KP, Manion EE, Ying M, Schulman BA, Oliver PM. Itch WW Domains Inhibit Its E3 Ubiquitin Ligase Activity by Blocking E2-E3 Ligase Trans-thiolation. J Biol Chem. 2015; 290:23875-23887.

43. Noyes NC, Hampton B, Migliorini M, Strickland DK. Regulation of Itch and Nedd4 E3 Ligase Activity and Degradation by LRAD3. Biochemistry. 2016; 55:1204-1213.

44. Li Y, Zhou Z, Alimandi M, Chen C. WW domain containing E3 ubiquitin protein ligase 1 targets the full-length ErbB4 for ubiquitin-mediated degradation in breast cancer. Oncogene. 2009; 28:2948-2958.

45. Panner A, Crane CA, Weng C, Feletti A, Fang S, Parsa AT, Pieper RO. Ubiquitin-specific protease 8 links the PTENAkt-AIP4 pathway to the control of FLIPS stability and TRAIL sensitivity in glioblastoma multiforme. Cancer Res. 2010; 70:5046-5053.

46. Perez-Mancera PA, Rust AG, van der Weyden L, Kristiansen G, Li A, Sarver AL, Silverstein KA, Grützmann R, Aust D, Rümmele P, Knösel T, Herd C, Stemple DL, et al. The deubiquitinase USP9X suppresses pancreatic ductal adenocarcinoma. Nature. 2012; 486:266-270.

47. Mouchantaf R, Azakir BA, McPherson PS, Millard SM, Wood SA, Angers A. The ubiquitin ligase itch is autoubiquitylated in vivo and in vitro but is protected from degradation by interacting with the deubiquitylating enzyme FAM/USP9X. J Biol Chem. 2006; 28:38738-38747.

48. Wu X, Yen L, Irwin L, Sweeney C, Carraway KL, 3rd. Stabilization of the E3 ubiquitin ligase Nrdp1 by the deubiquitinating enzyme USP8. Mol Cell Biol. 2004; 24:7748-7757.

49. Cox JL, Wilder PJ, Wuebben EL, Ouellette MM, Hollingsworth MA, Rizzino A. Context-dependent function of the deubiquitinating enzyme USP9X in pancreatic ductal adenocarcinoma. Cancer Biol Ther. 2014; 15:1042-1052.
50. Gaborit N, Abdul-Hai A, Mancini M, Lindzen M, Lavi S, Leitner O, Mounier L, Chentouf M, Dunoyer S, Ghosh M, Larbouret $\mathrm{C}$, Chardès T, Bazin $\mathrm{H}$, et al. Examination of HER3 targeting in cancer using monoclonal antibodies. Proc Natl Acad Sci USA. 2015; 112:839-844.

51. Dai W, Li Y, Zhou Q, Xu Z, Sun C, Tan X, Lu L. Cetuximab inhibits oral squamous cell carcinoma invasion and metastasis via degradation of epidermal growth factor receptor. J Oral Pathol Med. 2014; 43:250-257.

52. Sala G, Traini S, D’Egidio M, Vianale G, Rossi C, Piccolo E, Lattanzio R, Piantelli M, Tinari N, Natali PG, Muraro R, Iacobelli S, et al. An ErbB-3 antibody, MP-RM-1, inhibits tumor growth by blocking ligand-dependent and independent activation of ErbB-3/Akt signaling. Oncogene. 2012; 31:1275-1286.

53. Belleudi F, Marra E, Mazzetta F, Fattore L, Giovagnoli MR, Mancini R, Aurisicchio L, Torrisi MR, Ciliberto G. Monoclonal antibody-induced ErbB3 receptor internalization and degradation inhibits growth and migration of human melanoma cells. Cell Cycle. 2012; 11:1455-1467.

54. Broussas M, Dupont J, Gonzalez A, Blaecke A, Fournier M, Corvaïa N, Goetsch L. Molecular mechanisms involved in activity of h7C10, a humanized monoclonal antibody, to IGF-1 receptor. Int J Cancer. 2009; 124:2281-2293.

55. Pace E, Adams S, Camblin A, Curley M, Rimkunas V, Nie L, Iadevaia S, Tan G, Baum J, Czibere AG, Lugovskoy A. Effect of MM-141 on gemcitabine and nab-paclitaxel potentiation in preclinical models of pancreatic cancer through induction of IGF-1R and ErbB3 degradation. J Clin Oncol. 2015; 33: Abstract 289.

56. Ren XR, Wang J, Osada T, Mook RA Jr, Morse MA, Barak LS, Lyerly HK, Chen W. Perhexiline promotes HER3 ablation through receptor internalization and inhibits tumor growth. Breast Cancer Res. 2015; 17:20.

57. Melino G, Knight RA, Cesareni G. Degradation of $\mathrm{p} 63$ by Itch. Cell Cycle. 2006; 5:1735-1739.

58. Rossi M, De Laurenzi V, Munarriz E, Green DR, Liu YC, Vousden KH, Cesareni G, Melino G. The ubiquitin-protein ligase Itch regulates p73 stability. Embo J. 2005; 24:836-848.

59. Vecchione A, Marchese A, Henry P, Rotin D, Morrione A. The Grb10/Nedd4 complex regulates ligand-induced ubiquitination and stability of the insulin-like growth factor I receptor. Mol Cell Biol. 2003; 23:3363-3372.

60. Bouyain S, Leahy DJ. Structure-based mutagenesis of the substrate-recognition domain of Nrdp1/FLRF identifies the binding site for the receptor tyrosine kinase ErbB3. Protein Sci. 2007; 16:654-661.

61. Chen C, Liu Y, Zheng D. An agonistic monoclonal antibody against DR5 induces ROS production, sustained JNK activation and Endo G release in Jurkat leukemia cells. Cell Res. 2009;19:984-995.

62. Stein R, Gupta P, Chen X, Cardillo TM, Furman RR, Chen S, Chang CH, Goldenberg DM. Therapy of B-cell malignancies by anti-HLA-DR humanized monoclonal 
antibody, IMMU-114, is mediated through hyperactivation of ERK and JNK MAP kinase signaling pathways. Blood. 2010; 115:5180-5190.

63. Angers A, Ramjaun AR, McPherson PS. The HECT domain ligase itch ubiquitinates endophilin and localizes to the trans-Golgi network and endosomal system. J Biol Chem. 2004; 279:11471-11479.

64. Malik R, Soh UJ, Trejo J, Marchese A. Novel roles for the E3 ubiquitin ligase atrophin-interacting protein 4 and signal transduction adaptor molecule 1 in G protein-coupled receptor signalling. J Biol Chem. 2012; 287:9013-9027.
65. Thomas G, Chardès T, Gaborit N, Mollevi C, Leconet W, Robert B, Radosevic-Robin N, Penault-Llorca F, Gongora C, Colombo PE, Lazrek Y, Bras-Goncalves R, et al. HER3 as biomarker and therapeutic target in pancreatic cancer: new insights in pertuzumab therapy in preclinical models. Oncotarget. 2014; 5:7138-7148. doi: 10.18632/oncotarget.2231. 